University of Tennessee Health Science Center

UTHSC Digital Commons

\title{
$5-2011$
}

\section{The Relationship between Lower Extremity Bone Mass and Body Mass Index in a NHANES Adolescent Population}

James Randall Post

University of Tennessee Health Science Center

Follow this and additional works at: https://dc.uthsc.edu/dissertations

Part of the Pediatric Nursing Commons

\section{Recommended Citation}

Post, James Randall , "The Relationship between Lower Extremity Bone Mass and Body Mass Index in a NHANES Adolescent Population" (2011). Theses and Dissertations (ETD). Paper 214. http://dx.doi.org/ 10.21007/etd.cghs.2011.0250.

This Dissertation is brought to you for free and open access by the College of Graduate Health Sciences at UTHSC Digital Commons. It has been accepted for inclusion in Theses and Dissertations (ETD) by an authorized administrator of UTHSC Digital Commons. For more information, please contact jwelch30@uthsc.edu. 


\title{
The Relationship between Lower Extremity Bone Mass and Body Mass Index in a NHANES Adolescent Population
}

\author{
Abstract \\ The effect of body mass index (BMI) on bone mineral content (BMC) among adolescents has been \\ researched yielding mixed results. This study explored the relationship of left lower extremity (LLE) BMC \\ on BMI across the spectrum of weight in a large nationally representative group of adolescents. This \\ descriptive study used secondary data from the publically accessible, cross-sectional survey files of the \\ 1999-2004 Continuous National Health Assessment and Nutritional Examination Survey (NHANES) that \\ contained whole body dual energy X-ray absorptiometry (DXA) data as well as BMI calculations looking at \\ the adolescent population 12- to19-year-olds at the time of the exam. The sample contained 5416 \\ adolescents with males 59.7\%; with Caucasian 27.3\%, African American $32.1 \%$, and Mexican American \\ $34.0 \%$; and with underweight $3.5 \%$, normal weight $61.8 \%$, overweight $15.8 \%$ and obese $18.9 \%$. The \\ analysis of the data used SAS survey regression examining 90 domains from the sample based on the \\ three demographic groups of gender, race/ethnicity, and age category and their possible permutations. \\ Each domain survey regression was performed five times, once for each of the five imputations of DXA \\ data from each survey participant's DXA scan. The five regression results were averaged in accordance \\ with NHANES guidelines to yield a composite regression estimates with associated standard errors as \\ results for the different domains. Results revealed a positive, linear relationship between BMI to LLE BMC \\ with $p<0.0001$ for most of the domains. Results also revealed that the relationship between BMI to LLE \\ $B M C$ depended greatly on the demographic factors of gender, race/ethnicity and age category. \\ Conclusions: The greater the slope of the regression line for a particular domain meant that the domain's \\ LLE BMC was more influenced by change in BMI. The rate that BMI affects BMC varies according to \\ gender, race/ethnicity, and age and must be examined accordingly.

\section{Document Type} \\ Dissertation \\ Degree Name \\ Doctor of Philosophy $(\mathrm{PhD})$ \\ Program \\ Nursing \\ Research Advisor \\ Patricia Cowan, Ph.D. \\ Keywords \\ Adolescents, BMI, Bone mass, CDC, DXA, NHANES \\ Subject Categories \\ Medicine and Health Sciences | Nursing | Pediatric Nursing
}




\title{
THE RELATIONSHIP BETWEEN LOWER EXTREMITY BONE MASS AND BODY MASS INDEX IN A NHANES ADOLESCENT POPULATION
}

\author{
A Dissertation \\ Presented for \\ The Graduate Studies Council \\ The University of Tennessee \\ Health Science Center
}

\author{
In Partial Fulfillment \\ Of the Requirements for the Degree \\ Doctor of Philosophy \\ From The University of Tennessee
}

By

James Randall Post

May 2011 
Copyright $(\subset 2011$ by James Randall Post All rights reserved 


\section{DEDICATION}

This work is dedicated to my Savior, Jesus Christ. Hopefully one day I will be found to be workman approved by God. A sinner saved by grace who loved mercy, tried to be just, and tried to walked humbly with my God. 


\section{ACKNOWLEDGEMENTS}

First, I would like to acknowledge the tremendous work of my dissertation committee: Drs. Patty Cowan, Michael Carter, Diane Pace, Betsy Tolley, and Fran Tylavsky. I'm sure this study would not have been tackled without their time, effort, and encouragement. Thank you for the numerous hours of training, education, support, guidance, prodding and time you provided to me throughout the dissertation process. Also, I wish to thank Dr. Shirleatha Lee, who graciously proofread the initial draft of Chapter 1 and Chapter 3.

Secondly, I would like to acknowledge the work of the National Center for Health Statistics (NCHS) and all its agents in conducting the research, gathering and organizing the data, and publicly posting the data from the Continuous National Health and Nutrition Examination Survey (NHANES) from 1999-2004. Without whose data, this dissertation could not have been conducted.

Thirdly, I would like to acknowledge the support and patience of my wife, Tara Watson-Post. Her never-ending support provided the motivation for me to finish this dissertation.

Finally, I would like to acknowledge the full financial support provided by the United States (US) Army for these past three years of graduate education while pursuing my doctorate in nursing. 


\begin{abstract}
The effect of body mass index (BMI) on bone mineral content (BMC) among adolescents has been researched yielding mixed results. This study explored the relationship of left lower extremity (LLE) BMC on BMI across the spectrum of weight in a large nationally representative group of adolescents. This descriptive study used secondary data from the publically accessible, cross-sectional survey files of the 19992004 Continuous National Health Assessment and Nutritional Examination Survey (NHANES) that contained whole body dual energy X-ray absorptiometry (DXA) data as well as BMI calculations looking at the adolescent population 12- to 19-year-olds at the time of the exam. The sample contained 5,416 adolescents with males 59.7\%; with Caucasian 27.3\%, African American 32.1\%, and Mexican American 34.0\%; and with underweight $3.5 \%$, normal weight $61.8 \%$, overweight $15.8 \%$ and obese $18.9 \%$. The analysis of the data used SAS survey regression examining 90 domains from the sample based on the three demographic groups of gender, race/ethnicity, and age category and their possible permutations. Each domain survey regression was performed five times, once for each of the five imputations of DXA data from each survey participant's DXA scan. The five regression results were averaged in accordance with NHANES guidelines to yield a composite regression estimates with associated standard errors as results for the different domains. Results revealed a positive, linear relationship between BMI to LLE BMC with $\mathrm{p}<0.0001$ for most of the domains. Results also revealed that the relationship between BMI to LLE BMC depended greatly on the demographic factors of gender, race/ethnicity and age category. Conclusions: The greater the slope of the regression line for a particular domain meant that the domain's LLE BMC was more influenced by change in BMI. The rate that BMI affects BMC varies according to gender, race/ethnicity, and age and must be examined accordingly.
\end{abstract}




\section{TABLE OF CONTENTS}

CHAPTER 1. INTRODUCTION .........................................................................................

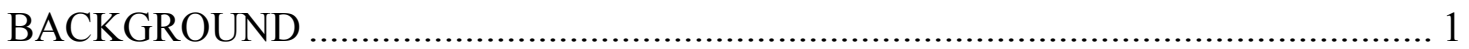

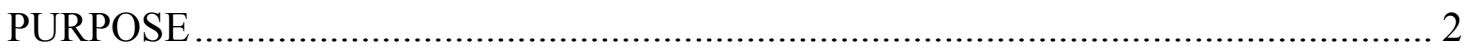

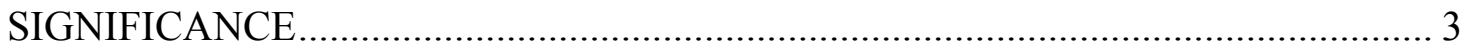

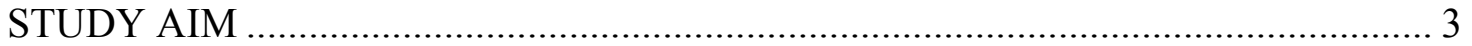

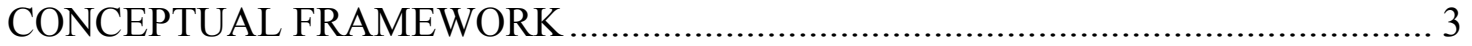

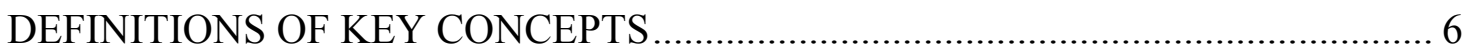

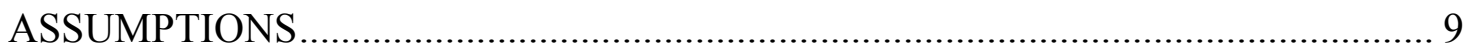

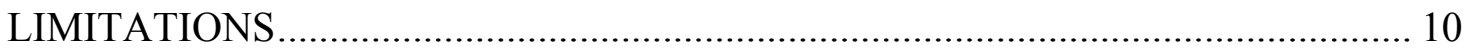

CHAPTER 2. REVIEW OF LITERATURE .........................................................

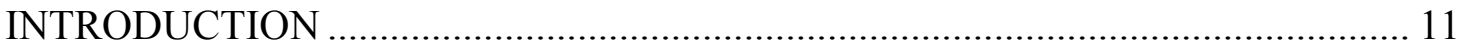

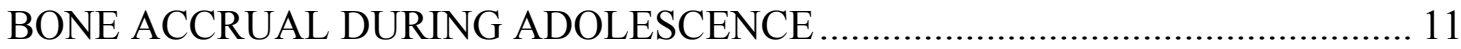

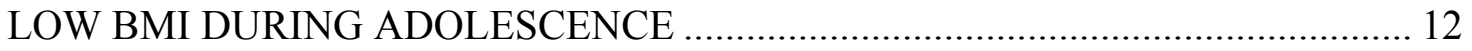

HIGH BMI DURING ADOLESCENCE ........................................................... 13

CHAPTER 3. METHODS ….................................................................................................16

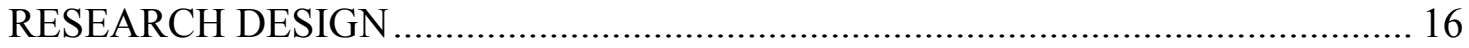

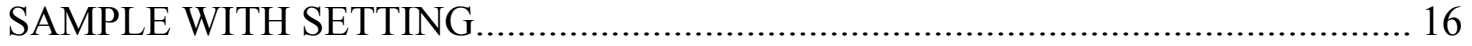

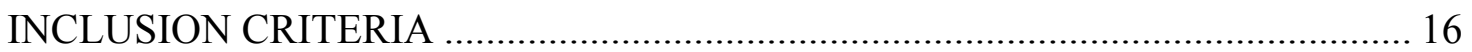

EXCLUSION CRITERIA ….............................................................................. 17

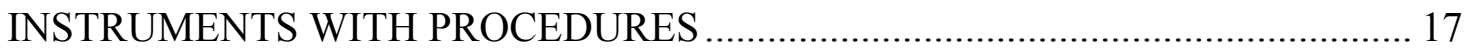

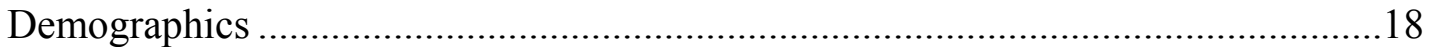

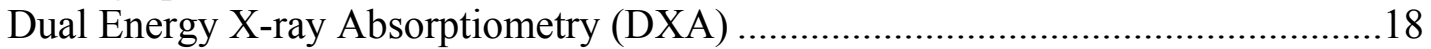

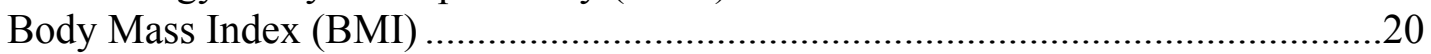

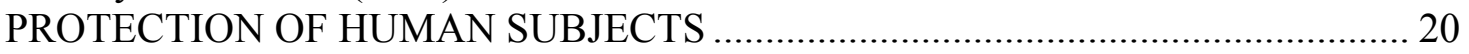

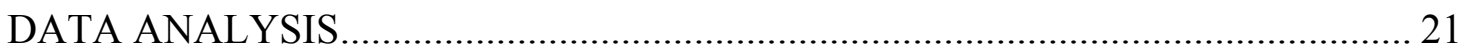

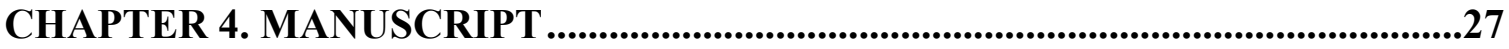

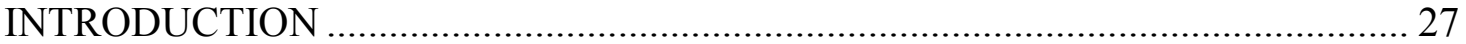

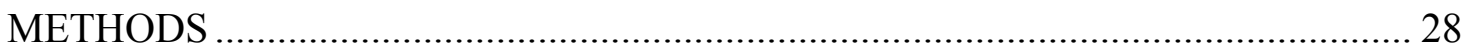

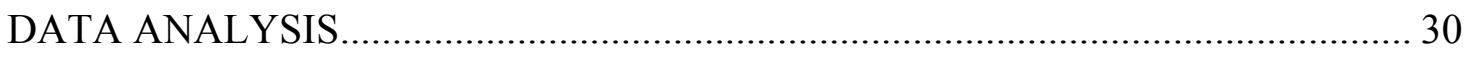

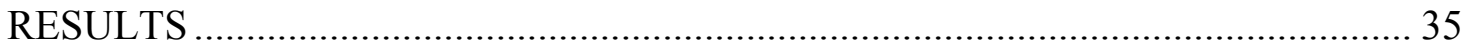

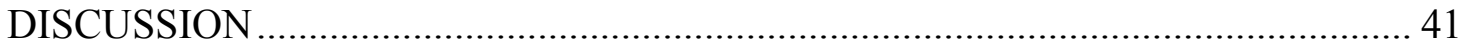

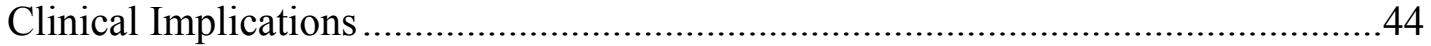

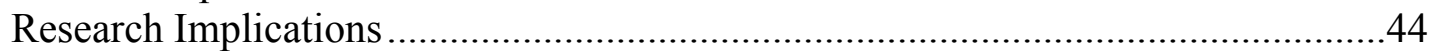

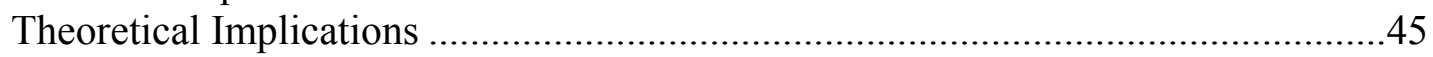

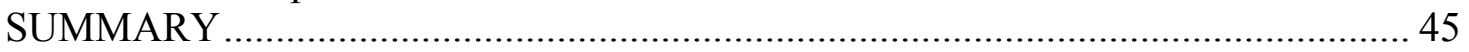

LIST OF REFERENCES................................................................................................... 46 


\section{APPENDIX. UNIVERSITY OF TENNESSEE HEALTH SCIENCE CENTER INSTITUTIONAL REVIEW BOARD LETTER OF APPROVAL.....51}

VITA 


\section{LIST OF TABLES}

Table 3.1. Level II domains as derived from their demographic groups

$(\mathrm{N}=5416)$

Table 3.2. Level III domains permutations of two of the three demographic groups $(\mathrm{N}=5416)$.

Table 3.3. Level IV domains permutations from all three of the demographic groups $(\mathrm{N}=5416)$

Table 4.1. Level II domains as derived from their demographic groups

$(\mathrm{N}=5416)$

Table 4.2. Level III domains permutations of two of the three demographic groups $(\mathrm{N}=5416)$.

Table 4.3. Level IV domains permutations from all three of the demographic groups $(\mathrm{N}=5416)$.

Table 4.4. Demographics of the adolescent sample from the 1999-2004

NHANES surveys who had DXA and BMI assessments $(\mathrm{N}=5416)$.

Table 4.5. Left lower extremity bone mineral content for each of the five imputations in the total sample $(\mathrm{N}=5416)$. .36

Table 4.6. Survey regression results for left lower extremity bone mineral content on body mass index based on the average of the five imputations (Level I).

Table 4.7. Survey regression results left lower extremity bone mineral content on body mass index based on the average of the five imputations (Level IV). 


\section{LIST OF FIGURES}

Figure 1.1. Examples of non-mechanical factors influencing bone status.....................4

Figure 1.2. Bone mass vs. tissue strain (in microstrain) in the Mechanostat Theory........5

Figure 1.3. Body mass index as a modulator in Frost's Mechanostat Theory. .................7

Figure 4.1. Plot of left lower extremity on body mass index for male Caucasian 12to 13 -year-olds domain with the estimated regression line superimposed...42

Figure 4.2. Plot of left lower extremity bone mineral content on body mass index for male Caucasian 12- to 13 -year-olds domain by weight category................43 


\section{LIST OF ABBREVIATIONS}

\begin{tabular}{ll} 
AA & African American \\
BMC & bone mineral content \\
BMI & body mass index \\
CA & Caucasian \\
CAPI & Computer Assisted Personal Interviewing \\
CDC & Center for Disease Control and Prevention \\
CI & confidence interval \\
cm & centimeter \\
DXA & dual energy X-ray absorptiometry \\
gm & gram \\
ISIS & Integrated Survey Information System \\
kg & kilogram \\
LE & lower extremity \\
LLE & left lower extremity \\
LM & lean mass \\
MA & Mexican American \\
MEC & mobile examination centers \\
MESm & minimum effective strain for modeling \\
MESr & minimum effective strain for remodeling \\
N & size of population \\
NCHS & National Center for Health Statistics \\
NHANES & National Health and Nutritional Examination Surveys \\
OH & Other Hispanic \\
OR & Other Race \\
p & probability \\
PSU & population sampling units \\
RIDRETH2 & race and ethnicity variable two \\
SD & standard deviation \\
SE & standard error \\
UCSF & University of California, San Francisco \\
US & United States \\
& \\
\hline
\end{tabular}




\section{CHAPTER 1. INTRODUCTION}

\section{BACKGROUND}

Adolescence is an important phase for bone development with peak total bone mass usually obtained in early adulthood (Gordon et al., 2008). Adolescents accumulate more than $25 \%$ of adult bone mass during puberty; bones lengthen, widen and finally mineralize during the adolescent growth spurt (Rauch, 2005). Bone mass continues to accrue for approximately six months following the end of the adolescent growth spurt (Whiting et al., 2004).

Having excess weight during adolescence has repercussions on bone health. The increased prevalence of obesity during adolescence has in turn resulted in a myriad of acute and chronic conditions in this population, including musculoskeletal problems (CDC, 2010; Daniels et al., 2005). Overweight and obese adolescents have a higher prevalence of fractures, musculoskeletal discomfort, impaired mobility, and lower extremity (LE) mal-alignment than their normal weight peers (Taylor et al., 2006).

Research regarding the relationship of obesity to bone mineral content (BMC) has yielded equivocal results. In adults, increased body mass index (BMI) enhanced bone mass (Reid, 2002). Similarly, several studies support a positive association between BMI and bone density or BMC in youth. Cobayashi, Lopes, and Taddei (2005) reported that overweight and obese adolescents had higher bone mineral density than their normal weight counterparts. Ellis, Shypailo, Wong, and Abrams (2003) found that obese children have higher BMC compared with leaner children of normal adiposity, even when adjusted for height, age, gender, and ethnicity. Obesity during childhood and adolescence was related to increased vertebral bone density (Leonard, Shults, Wilson, Tershakovec, \& Zemel, 2004) and increased body BMC (Braillon, Berard, Chatelain, \& Pracros, 2002; Leonard, et al., 2004). Additionally, weight changes in obese, female adolescents were strongly related to changes in BMC and bone mineral density (Rourke, Brehm, Cassell, \& Sethuraman, 2003). Gender differences in the relationship of BMI and bone mass may be present. Sayers and Tobias (2010) found fat mass stimulated cortical bone mass in adolescent girls more than in adolescent boys.

In contrast, Goulding et al. (2000) found obese and overweight children and adolescents had lower than predicted bone mass and bone area for their size. They concluded that a "mismatch" occurs during bone development for overweight and obese children and adolescents. These findings were confirmed in a subsequent study (Goulding, Taylor, Jones, Manning, \& Williams, 2002) in which overweight and obese children and adolescents had lower BMC in their lumbar vertebrae than normal weight peers. This finding suggests that overweight children and adolescents do not increase spinal BMC to adequately compensate for their increased weight. Similarly, De Schepper, Van den Broeck, and Jonckheer (1995) found that older obese children and young obese adolescents had normal, not greater, spine bone mineral density. Researchers concluded in a study with 6- to 18-year-olds (Ackerman, Thornton, Wang, Pierson, \& Horlick, 2006) that individuals with greater fat mass will have lower BMC 
than individuals with greater lean mass. It is unclear what the true effect of increased BMI has on BMC in adolescents, despite the number of studies examining the effects of increased mass on BMC.

One measure of bone status is BMC (measured in grams $(\mathrm{gm})$ or bone mineral density (measured in grams/centimeter ${ }^{2}\left(\mathrm{gm} / \mathrm{cm}^{2}\right)$. Dual energy X-ray absorptiometry (DXA) is the gold standard for determining bone mineral density and/or BMC (National Osteoporosis Foundation, 2008). Qualities that make DXA the preferred densitometry technique include: speed, precision, safety, low cost, and widespread availability (Gordon et al., 2008). Studies, outlined in Wahner \& Fogelman (1994), employed scanned phantoms, which contain known qualities of bone ash within a known area, to determine DXA accuracy. Based on findings from these studies, DXA accuracy was shown to be $\geq 99 \%$ (Wahner \& Fogelman, 1994). This accuracy along with its other combination of qualities makes DXA an excellent choice for determining BMC.

Bone status can also be determined by its fragility, its ability to withstand fracture. Previously bone mineral density was considered the primary measure of bone fragility or bone strength. Both areal bone mineral density, measured by DXA, or volumetric bone mineral density, measured by quantitative computed tomography, have been used as measures of bone strength. In looking at bone fragility, researchers are considering that most bones are not isolated and have an associated muscle mass which provides support and strength to the bone. Therefore, the bone with its associated muscle mass should be thought of as a single unit composed of muscle with bone. This bonemuscle unit may provide a more effective method to determine bone fragility instead of bone mineral density alone (Beck et al., 2000; Gordon, et al., 2008). In children, the comparison of BMC and lean mass has been explored as possible measures for the strength of the bone-muscle unit when being used in fracture prediction (Gordon, et al., 2008). In order to understand the bone-muscle unit, it is necessary to examine each component of the bone-muscle unit. First examination of the bone component is critical to understanding any impact on the entire bone-muscle unit. This study will focus on this component. Future follow-up studies will focus on the impact of the associated muscle mass component and the comparison of these two integral components and their effect.

\section{PURPOSE}

The purpose of this study was to examine the relationship of BMI to LE BMC from the whole body DXA scan measurements of the Continuous National Health and Nutritional Examination Survey (NHANES) 1999-2004 population of adolescents aged 12- to 19-year-olds. This study was based on the premise that the lower extremities support the BMI of the individual. The hypothesis of this study was that higher BMI will be associated with greater LE BMC. 


\section{SIGNIFICANCE}

Since bone health for the life span is dependent on the accrual of bone during adolescence, it is important to understand the possible impact of adolescent overweight and obesity on bone health. The first step in this understanding is examining the relationship of BMI to BMC and bone mineral density of adolescents in a large reference population, like NHANES. After understanding the relationship of BMC on BMI, further studies can explore the relationship of lean mass on BMI and explore the relationship of the comparison of BMC and lean mass to BMI for clarification of the effect of BMI on the bone-muscle unit.

\section{STUDY AIM}

The aim of this study was to examine the functional form of the relationship of the independent variable BMI to left lower extremity (LLE) BMC for Caucasians, African Americans, and Mexican Americans adolescents aged 12- to 19-year-olds using the Continuous NHANES 1999-2004 data.

\section{CONCEPTUAL FRAMEWORK}

Bone development during adolescence is marked by significant increases especially during the pubertal growth spurt. Prior to 1995, the dominate view of bone development was based on the 1960 paradigm of bone physiology which considered bone status (bone health) dependent on the roles of osteoblasts and osteoclasts and the influence of non-mechanical factors such as hormones, gender, genetics, calcium, vitamin D, and other hormonal agents on these bone cells (Jee, 2000). In Figure 1.1, two examples demonstrate the 1960 paradigm in action.

To augment the deficiencies of the 1960 paradigm of bone physiology, Harold Frost developed a functional model of bone development based on his Mechanostat Theory (Jee, 2000). The Mechanostat Theory promotes the idea that mechanical factors rather than biological factors control the growth of postnatal bone development and mass. According to the Mechanostat Theory, "there is a minimum effective strain which must be exceeded to excite an adaptive response to mechanical overload" (Jee, 2000, p. 12). For strains below 100 microstrain (the remodeling threshold), osteoclast activity is stimulated resulting in bone loss. For strains above 1500 microstrain (the modeling threshold), osteoblast activity is stimulated resulting in bone gain. For strains between the thresholds of 100 and 1500 microstrain, osteoblast and osteoclast activity is balanced without net bone loss or gain. Figure 1.2 provides a graphical display of this concept.

The minimum effective strain for remodeling (MESr) and the minimum effective strain for modeling (MESm) are the set points of the mechanostat signaling to activate the osteoclasts and osteoblasts, respectively. This is similar to a thermostat signaling a furnace to decrease heat or increase heat. Just like the set point of a thermostat can be adjusted, the set points of the mechanostats can be adjusted. The mechanostat set points 


\begin{tabular}{|c|c|c|c|c|}
\hline Vitamin D & $\rightarrow$ & Osteoblasts & $\rightarrow$ & Increased bone mineralization \\
\hline Prednisone & $\rightarrow$ & Osteoclasts & $\rightarrow$ & Decreased bone mineralization \\
\hline
\end{tabular}

Figure 1.1. Examples of non-mechanical factors influencing bone status.

Modified with permission from Jee, W. S. (2000). Principles in bone physiology. Journal of Musculoskeletal and Neuronal Interaction, 1(1), 11-13. 


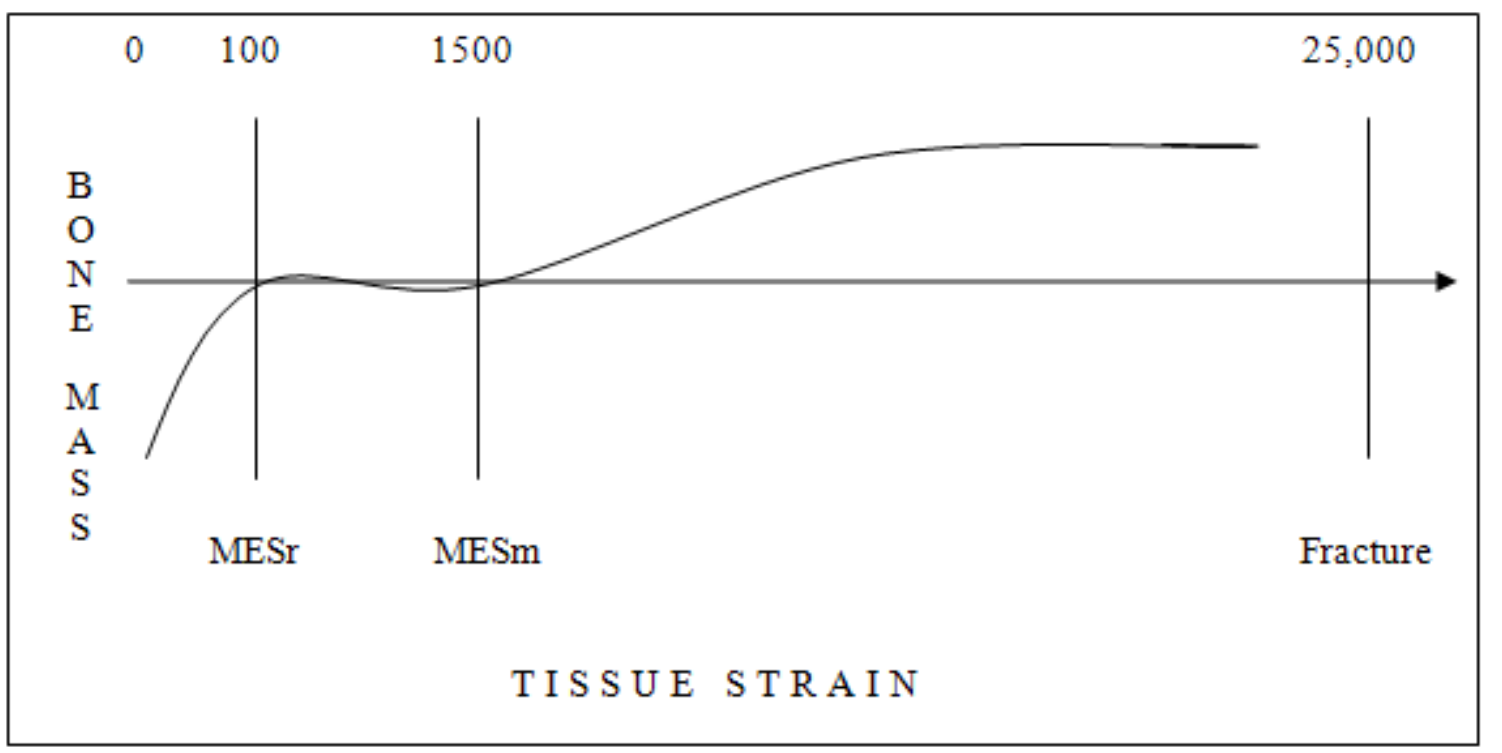

Figure 1.2. Bone mass vs. tissue strain (in microstrain) in the Mechanostat Theory.

Notes: MESr=bone mass loss with strains less than minimum effect strain for remodeling.

MESn=bone mass gain with strains greater than minimum effect strain for modeling. Fracture may occur at low bone mass with less strain or at high bone mass large strain. With strains between the MESr and MESm there is neither bone mass loss nor gain.

Modified with permission from Jee, W. S. (2000). Principles in bone physiology. Journal of Musculoskeletal and Neuronal Interaction, 1(1), 11-13. 
can be adjusted by modulators. These modulators include hormones, nutritional factors, behavioral factors, and environmental factors. These modulators may also affect the osteoblasts and/or osteoclasts as well as the muscle directly. "The central piece of bone regulation is the feedback loop between bone deformation (tissue strain) and bone strength. During growth this homeostatic system is continually forced to adapt to external challenges"(Schoenau \& Frost, 2002, p. 406). Figure 1.3 depicts a simplified functional model based on Frost's Mechanostat Theory with BMI as the modulator.

This simplified model illustrates BMI as a modulator. It is not known how this modulator affects the MESr and MESm set points of the mechanostat. The model is easier to understand when following two examples from the NHANES data set through the model. Consider a normal weight adolescent of a certain height with normal BMI less than 85 percentile for age within Frost's Mechanostat Theory using the modulator of BMI (a behavioral factor). When the normal weight adolescent is walking, the normal weight does not require a significant increase in the muscle force in the LE to move the leg. (Since muscle force is not directly measured in the NHANES data sets, lean mass of the LE from the DXA scan could be used as a surrogate measure for muscle force.) There is no increase in tissue strain and the MESm of the mechanostat is not achieved. Thus, the mechanostat does not signal the osteoblasts or the osteoclasts to increase activity and no increase nor decrease in bone mass occurs. Bone mass of the $\mathrm{LE}$ is measured by the BMC of the LE. Bone strength and tissue strain remain the same.

Now consider an overweight adolescent with the same height within Frost's Mechanostat Theory. When the adolescent is walking, the increase in weight requires an increase in the muscle force to move the LE. This causes an increase in the tissue strain. If the MESm is achieved, the mechanostat activates and signals the osteoblasts to increase bone mass. Bone mass builds up, thereby increasing the bone strength. This continues until bone strength is great enough that tissue strain is reduced below the upper set point of the MESm. Then, the mechanostat stops signaling the osteoblasts to increase bone mass. This simplified walk through of the model with BMI as the modulator assumes all other modulators are constant. However, modulators do not work in isolation. In reality multiple modulators are working at the same time. Some modulators, like calcium and vitamin $\mathrm{D}$, have additive effects working to promote bone gain. Other modulators, like prednisone and weight-bearing activity, have opposing affects on bone accrual. Some modulators (physical activity) increase muscle force, some (growth hormone) increase bone length, while others increase (estrogen) or decrease (testosterone) the MESr and/or MESm set points of the mechanostat. Some modulators (smoking tobacco) may have a direct impact on the osteoclasts and/or osteoblasts.

\section{DEFINITIONS OF KEY CONCEPTS}

The following concepts were used in this study and are defined in this section.

- Adolescent is an individual who is older than 144 months (12 years) but less than 240 months (20 years) at the time of the whole body DXA scan. 


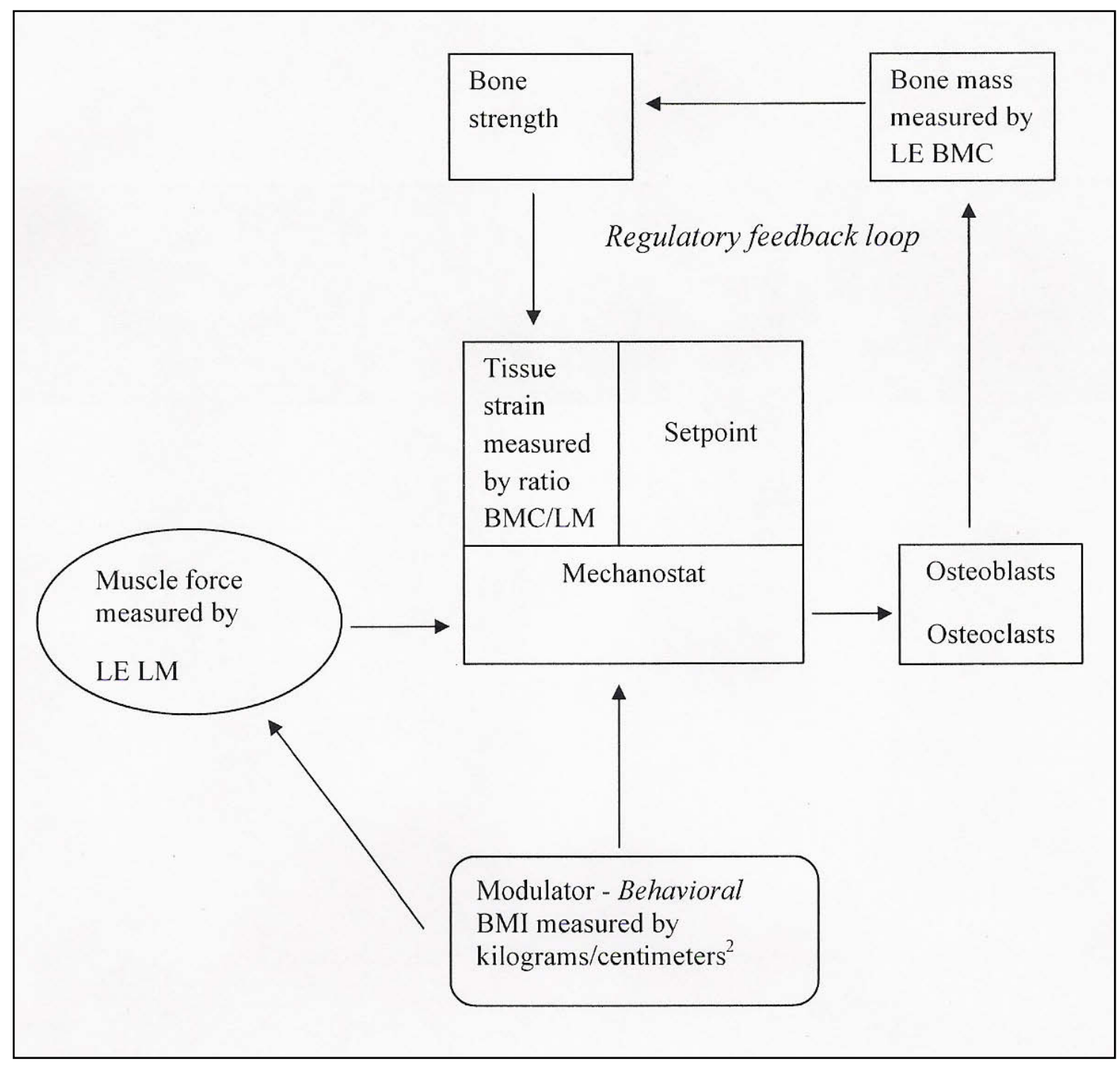

Figure 1.3. Body mass index as a modulator in Frost's Mechanostat Theory.

Note: $\mathrm{BMC}=$ bone mineral content, $\mathrm{LM}=$ lean mass, $\mathrm{LE}=$ lower extremity.

Modified with permission from Schoenau, E., \& Frost, H. M. (2002). The "muscle-bone unit" in children and adolescents. Calcified Tissue International, 70(5), 405-407. doi: 10.1007/s00223-001-0048-8. 
- Obese adolescents are defined as those with a BMI $\geq 95$ th percentile based on the 2000 CDC growth charts BMI for age and gender (CDC, 2010).

- Overweight adolescents are defined as those with a BMI $\geq 85$ th percentile and $<95$ th percentile based on the 2000 CDC growth charts BMI for age and gender (CDC, 2010).

- Normal or healthy weight adolescents are defined as those with a BMI $\geq 5$ th percentile and $<85$ th percentile based on the 2000 CDC growth charts BMI for age and gender (CDC, 2010).

- Underweight adolescents are defined as those with a BMI $<5$ th percentile based on the 2000 CDC growth charts BMI for age and gender (CDC, 2010).

- Gender is either male or female as self-reported by the study participant.

- Race/ethnicity was based on self-report response to two questions on race and ethnicity. First, participants self-identified as Non-Hispanic White (Caucasian), Non-Hispanic Black (African American), Mexican American, Other Hispanic, and Other Race. Other Race category included multiracial and other single racial/ethnic groups not listed. Secondly, those individuals who chose multiracial initially then selected a main race (Caucasian, African American, Mexican American or other). These individuals were re-classified based on the main race that they chose. If the multiracial participants did not identify a main race on the follow-up question, they remained coded as Other Race. For the current study, the main race/ethnicity categories were Caucasian, African American, and Mexican American.

- Dual energy X-ray absorptiometry (DXA) densitometer uses two different levels of low energy photons from either an X-ray or gamma source. The photon beams are attenuated, that is some of the photons are scattered and do not pass through the object to the detector while the remaining photons pass through the object to the detector. The attenuation of the photon beam is directly related to the density or the thickness of objects in the path of the beam. By comparing the attenuation of the two different levels of photon beams over the same area, the software of the DXA scanner can determine the density of the object. The DXA can differentiate bone versus soft tissue. Having discriminated bone from soft tissue, the DXA scanner can determine the density of the bone as a result of varying bone thickness for the scanned area. The bone is measured as BMC in gm for a certain area of interest and bone mineral density in $\mathrm{gm} / \mathrm{cm}^{2}$ for the BMC /area of bone measured in the area of interest. The DXA scanner is also capable of providing measurements of the lean mass in gm and the fat mass in gm for each area of interest, since their densities are different from bone and each other. The whole body DXA scan for this study provided data based on the total body and each of the seven regions of interest; head, trunk, pelvis, both arms and both legs. 
- Lower extremity is the entire leg with foot and toes but does not include the pelvis area. The whole body DXA scan used the manufacturer's defined region of interest for each of the regions including each LE. The LE provides support for the entire body during weight-bearing.

- Bone mineral content is the amount of mineralized bone, detected within a defined region of the scan. The BMC is measured in gm.

- Bone mineral density is the BMC found within an area of bone. Bone mineral density is calculated by dividing the BMC by the area of mineralized bone within the defined region of the scan. Bone mineral density is measured in $\mathrm{gm} / \mathrm{cm}^{2}$.

- Lean mass is the amount of fat and bone free soft tissue within a defined region. Lean mass is measured in gm. Lean mass is almost equivalent to muscle mass in the upper and lower extremities, since there are no other organs present unlike the trunk, pelvis and head.

- Bone-muscle unit is the complex comprised of the bone and its associated muscle mass.

- Modulator is a non-mechanical agent that adjusts the set points of the mechanostat, helping or hindering bone accrual. These modulators include hormones, nutritional factors, behavioral factors, and environmental factors. Examples of hormone modulators include growth hormone, parathyroid hormone, and sex hormones. Calcium and vitamin D are examples of nutritional modulators. Increased BMI, physical activity, sedentary lifestyle are examples of behavioral modulators. Environmental modulator is illustrated by smoking tobacco. For this study, BMI was the only modulator examined.

\begin{abstract}
ASSUMPTIONS
The NHANES data sets did not collect information on Tanner staging or maturation level of the adolescents. As a result, height was assumed as the surrogate measure for maturity. Height is included as a component of the independent variable BMI.

Increases in BMI will have the most impact on the bone and muscle of the lower extremities; therefore, BMC in the lower extremities would be the best DXA measurements to examine to determine the effect of BMI on bone status. The BMC of the LLE was chosen as the dependent variable to ensure consistency.
\end{abstract}




\section{LIMITATIONS}

The NHANES data sets were not from a random sample. The NHANES sampled the civilian, non-institutionalized populations of the United States. They over-sampled certain select subpopulations including low-income persons, persons over 60 years of age, African Americans, Mexican Americans and adolescents 12- to 19-year-olds. The findings from non-random studies may be confounded and may not be generalized to the entire population. There may exist a confounding variable, which has not been controlled (Polit \& Beck, 2008).

This study only examined one modulator, BMI. Previous studies have identified a number of factors which could be modulators affecting bone mass development. While some of these factors were collected as part of the NHANES data sets, the data were not collected in a consistent manner for the entire adolescent subpopulation. Individuals above 16 years of age answered questions directly, while proxies answered questions for those below 16 years of age. The results of some lab values, in particular, vitamin D levels were affected by drift and were considered suspect. Future studies will be needed to address the impact of these factors as possible confounders.

All DXA scans for the Continuous NHANES 1999-2004 data sets were reviewed and analyzed by the University of California, San Francisco (UCSF), Department of Radiology. The UCSF applied invalidity codes to the entire scan or selected body regions when data could not be accurately analyzed. Data could not be accurately analyzed as a result of presence of jewelry and other objects not removed by participants, the presence of non-removable objects, arm/leg overlap, body parts out of scanner area, positioning problems, participant motion during the scan and other reasons. The data that could not accurately be analyzed were coded as missing. Multiple imputations of the missing data were performed to resolve the problem of potential biases due to missing DXA data. Five imputations were performed for the missing data. There are five data files, each containing a different imputation of the missing data. Some of the imputations contained highly variable data. Due to extreme nature of their variability of these imputations, this limited data set was not included with the DXA data sets and placed in a separate file (CDC. NCHS, 2010a). This separate data file was not included in this study. 


\section{CHAPTER 2. REVIEW OF LITERATURE}

\section{INTRODUCTION}

This review of literature examines the key components of this study. Initially bone mass accrual process during adolescence is reviewed with gender and racial differences examined. Secondly, the effects of decreased BMI during adolescence on bone mass accrual and low BMI consequences on bone health are explored. Finally, the effects of increased BMI on bone mass accrual and high BMI consequences on bone health are examined.

\section{BONE ACCRUAL DURING ADOLESCENCE}

Adolescence is a critical time for bone mass accrual. More than half of the peak bone mass, the largest amount of bone mass accumulated during a lifetime, is accrued during adolescence (Loud \& Gordon, 2006). Adolescence is a period of rapid growth and body maturation. Peak height velocity, commonly referred to as the pubertal growth spurt, is the period of rapid increase in height. In prior research among Caucasian adolescents (Bailey, Martin, McKay, Whiting, \& Mirwald, 2000), peak height velocity occurred for males at mean age of 13.4 years (standard deviation (SD)=1.0 years) and for females at mean age of 11.8 years $(\mathrm{SD}=0.9$ years). Generally peak velocity for $\mathrm{BMC}$ accrual continued after height development for 7 months in males and over 8 months in females. After the pubertal growth spurt, bone mass continues to accrue (Bachrach, Hastie, Wang, Narasimhan, \& Marcus, 1999; Bonjour, Theintz, Buchs, Slosman, \& Rizzoli, 1991; Magarey et al., 1999) during adolescence but at a slower rate into early adulthood. Thus as the adolescent ages, bone mass continues to accrue; therefore, BMC increases throughout adolescence.

The timing and length of puberty and its effect on bone mass in healthy males and females has been studied. In a longitudinal study, (Gilsanz et al., 2011) researchers found that bone mass at skeletal maturity was inversely related to the time of puberty onset, while independent of the length of puberty. In this population, the duration of puberty was the same for African Americans, Caucasians, Hispanics and Asians. Healthy males and females who started puberty a year later than the average age of puberty (10.7 years for females; 11.7 years for males) had 5\% less BMC at all skeletal sites, while those who started puberty a year earlier had 5\% more BMC at all skeletal sites. Additionally, fast and slow maturing adolescents achieved similar peak bone mass; therefore, differences in pubertal length did not significantly affect bone mass accrual.

Gender significantly impacts bone mass accrual during puberty. Males had higher levels of BMC at all skeletal sites (Gilsanz, et al., 2011; Kalkwarf et al., 2007) and higher rates of bone accrual than females (Kalkwarf, et al., 2007). Bone mass accrual "accelerated and plateaued earlier in females than males" (Bachrach, et al., 1999, p. 4706). It has been theorized that growth hormone is augmented by the increasing levels

of sex steroids enhancing new bone formation. Estradiol suppresses bone resorption, 
which decreases turnover, thus increasing bone density. Sex hormones have anabolic effects on bone accrual and increased muscularity (Davies, Evans, \& Gregory, 2005). In accordance with Frost's Mechanostat Theory (Schoenau \& Frost, 2002), increased muscularity leads to increased bone mass.

Racial and ethnic differences in bone mass accrual can also be seen in puberty. In a longitudinal study of 423 healthy male and females (aged 9- to 25-year-olds), researchers (Bachrach, et al., 1999) found that at each age level African Americans had consistently higher mean bone mineral density of the whole body, lumbar spine, femoral neck and total hip and whole body BMC/ height than the non-African American (Caucasian, Hispanic and Asian) races in the study. African American males mean areal bone mineral density was respectively $0.025,0.03$, and $0.05 \mathrm{gm} / \mathrm{cm}^{2}$ greater for spine, whole body and total hip than the mean for non-African American males. Similarly, African American females mean areal bone mineral density was $0.06 \mathrm{gm} / \mathrm{cm}^{2}$ greater at the spine and total hip and $0.05 \mathrm{gm} / \mathrm{cm}^{2}$ for whole body than the mean for non-African American females.

There were differences noted between the non-African American races as well (Bachrach, et al., 1999). Compared to Caucasians, Hispanic and Asian males had lower whole body and total hip bone mineral density mean. Hispanic males had lower spinal bone mineral density than Asian or Caucasian males. Hispanic females had slightly higher or same mean for whole body and total hip bone mineral density as Caucasian females. Asian females had lower whole body bone mineral density than Hispanic and Caucasian females, who had similar means. In a different longitudinal study (Kalkwarf, et al., 2007) of 1554 healthy children aged 6- to 16-year-olds, researchers again found African Americans to have higher bone mineral density at the whole body, lumbar spine, total hip, femoral neck, and forearm and BMC of whole body and lumbar spine. African Americans had higher bone mineral density and BMC $(\mathrm{p}<0.0001)$ when compared with other ethnic groups at all skeletal sites. Reference values for BMC were proposed for African American children based on age and gender. However, among the other ethnic groups, it was not possible to determine reference values for each ethnic group as the differences in BMC were not consistent across the various skeletal sites for males and females. Therefore, ethnic groups were combined and reference ranges for BMC in nonAfrican Americans were developed. These studies have contributed to our knowledge of the relationship between ethnicity, gender, and age to BMC in healthy children and adolescents. However, in adolescents, the relationship of BMI to BMC within age, gender, and ethnic/racial groups has not been elucidated.

\section{LOW BMI DURING ADOLESCENCE}

While the prevalence of low body weight in healthy adolescents is low $(3.8 \%)$, (Fryar \& Ogden, 2009), research supports the relationship of low body weight to low $\mathrm{BMC}$ in healthy adolescents. Typically studies have examined differences in BMC between adolescents with low body weight attributed to a disease (Bishop et al., 2008) [such as cystic fibrosis (Buntain et al., 2006) or anorexia nervosa (Misra et al., 2004; Soyka et al., 2002)] or overtraining [athletes (Nattiv, 2000)] to their normal weight peers. 
Galusca et al (2008) reported that young Caucasian females (18- to 30-year-olds) with low BMI, close to normal body composition and without hormonal abnormalities, had similar lumbar and femoral bone mineral density to young females with anorexia nervosa. Both the groups had lower bone mineral density than a control group of healthy, normal weight females. These findings were confirmed in a study by Fernandez-Garcia et al. (2009) in which older Caucasian adolescents with anorexia nervosa and healthy, agematched, peers with low body weight exhibited similar low BMC compared to healthy, normal weight, age-matched adolescents. Adolescents, who adhere to strict diets for weight control, may fail to meet the caloric, calcium, and protein demands their developing bodies need. Adolescent women may also have low bone density, who repeatedly diet to lose weight even if they are not underweight. Adolescents with low bone mass, whatever the reason, are at increased risk for fracture (Office of Surgeon General, 2004).

\section{HIGH BMI DURING ADOLESCENCE}

Overweight and obese adolescents have increased epidemically during the last decade. According to data from NHANES 2007-2008, (Ogden, Carroll, Curtin, Lamb, \& Flegal, 2010) over one third of adolescents are overweight (males:35.0\%; females:33.3\%), with the highest prevalence occurring in minorities. Adolescent overweight prevalence rates by race/ethnicity groups were: $31.3 \%$ for Caucasians, $39.5 \%$ for African Americans, 41.2\% for Hispanics, and 44.1\% for Mexican Americans. Alarmingly, almost one out of every five (18.1\%) adolescents is obese (Ogden, Carroll, Curtin, Lamb, \& Flegal, 2010).

Research regarding the relationship of obesity to BMC accrual has yielded equivocal results. In adults, increased BMI enhanced bone mass (Reid, 2002). Similarly, several studies support a positive association between BMI and bone density or BMC in youth. Cobayashi, Lopes, and Taddei (2005) reported that overweight and obese adolescents had higher bone mineral density than their normal weight counterparts. Ellis, Shypailo, Wong, and Abrams (2003) found that obese children have higher BMC compared with leaner children of normal adiposity, even when adjusted for height, age, gender, and ethnicity. Obesity during childhood and adolescence was related to increased vertebral bone density (Leonard, et al., 2004) and increased body BMC (Braillon, et al., 2002; Leonard, et al., 2004). Additionally, weight changes in obese, female adolescents were strongly related to changes in BMC and bone mineral density (Rourke, et al., 2003). Gender differences in the relationship of BMI and bone mass may be present. Sayers and Tobias (2010) found fat mass stimulated cortical bone mass in adolescent girls more than in adolescent boys.

In contrast, Goulding et al. (2000) found obese and overweight children and adolescents had lower than predicted bone mass and bone area for their size. They concluded that a "mismatch" occurs during bone development for overweight and obese children and adolescents. These findings were confirmed in a subsequent study (Goulding, et al., 2002) in which overweight and obese children and adolescents had lower BMC in their lumbar vertebrae than normal weight peers. This suggests that 
overweight children and adolescents do not increase spinal BMC to adequately compensate for their increased weight. Similarly, De Schepper, Van den Broeck, and Jonckheer (1995) found that older obese children and young obese adolescents had normal, not greater, spine bone mineral density. Researchers concluded in a study with 6to 18-year-olds (Ackerman, et al., 2006) that individuals with greater fat mass will have lower BMC than individuals with greater lean mass. It is unclear what the true effect of increased BMI has on BMC in adolescents, despite the number of studies examining the effects of increased mass on BMC.

Having excess weight during adolescence has repercussions on bone health. The increased incidence of obesity during adolescence has in turn resulted in a myriad of acute and chronic conditions in this population, including musculoskeletal problems (CDC, 2010; Daniels, et al., 2005). Overweight and obese adolescents have a higher prevalence of fractures, musculoskeletal discomfort, impaired mobility, and LE malalignment than their normal weight peers (Taylor, et al., 2006).

High body weight has naturally different effects on adolescents than low body weight. In looking at the pathophysiology of obesity and of being overweight, Daniels et al (2005) point out that studies frequently do not distinguish between obesity during adolescence and obesity with onset in adolescence. In addition to the risks occurring in adolescence, the risks of childhood and their effects on bone must be considered. Obese children (Pollack, 2008; Schwarz \& Freemark, 2010) have a higher prevalence of genu valgum, slipped capital femoral epiphysis, and tibia vara. In the developing bone of children, excess weight (Schwarz \& Freemark, 2010) can cause bending of the femur and tibia.

Adolescents with high BMI are at risk for forearm fracture (Goulding, Jones, Taylor, Williams, \& Manning, 2001). In this study, case patients who had sustained a forearm fracture were compared to controls who had not sustained a forearm fracture. Interestingly, more of the case patients were overweight (36 vs. 14) or obese (12 vs. 6) than the controls. Also, adolescents with high body weight are high risk for repeated forearm fracture (Goulding, Grant, \& Williams, 2005) (observed was 33.3\% versus expected $15.5 \%$ ). In both of these studies, it is understandable why adolescents with high BMI are at greater risk for this type of fracture. The force of impact for an adolescent with high BMI would be greater than an adolescent with normal BMI. The higher risk of fracture for obese children and adolescents (Taylor, et al., 2006) has been confirmed. In the chart review portion of the study, obese children and adolescents $(\mathrm{N}=227)$ were compared to non-obese $(\mathrm{N}=128)$. Documented fractures were higher in the obese group [odds ratio: 4.54; confidence interval: (1.6-13.2); $\mathrm{p}=0.0053$ ]. As the study points out, the force on the outstretched arm is greater for the obese. Dr. Lusting (Pollack, 2008) has observed and proposed that mechanical loading on the lower extremities may increase bone mineral density in the LE bones, while the same loading is not occurring in the upper extremities, which have a lower bone mineral density and a greater risk of fracture.

Other orthopedic problems are also higher in obese children and adolescents (Taylor, et al., 2006). The prevalence of reported joint pain was greater among the obese 
group compared to the non-obese group [odds ratio: 4.04; confidence interval: (1.5-10.6); $\mathrm{p}=0.0073$ ], with knee pain being the most common reported in $6.6 \%$ of obese charts and only $3.3 \%$ in non-obese charts. Another orthopedic concern was the mobility subscale on a quality of life questionnaire. Poorer quality of life on the mobility subscale was found in obese youth compared to the non-obese youth, indicating their perception of lack of mobility. This result may explain a finding from earlier research (Goulding, et al., 2001), where more overweight males had low self-assessment scores of physical activity than normal weight males.

There is a paucity of information regarding the relationship of BMI to bone health and bone accrual across the weight spectrum during adolescence. These studies generally compared a high BMI group to a normal weight group or a low weight group to a normal weight group. Despite, these numerous studies, the relationship of BMC on BMI is still unclear. This study was undertaken to fill this gap of knowledge and examine BMC across the entire weight spectrum within the same study. 


\section{CHAPTER 3. METHODS}

This study was undertaken to explore the relationship between BMI and DXA measurement of BMC in adolescents. This chapter provides a description of the research design, setting, sample, instruments, and procedures used in this study. In addition, the statistical analyses conducted to address the aim of this study are discussed. This chapter also addresses the measures used for the protection of human subjects.

\section{RESEARCH DESIGN}

This descriptive study used secondary data from the Continuous NHANES crosssectional surveys (CDC. NCHS, 2010a). Publically accessible files from the 1999-2000, 2001-2002, and 2003-2004 Continuous NHANES surveys which contained whole body DXA were accessed for this study. The documentation and public-use files are available at the NCHS NHANES website (CDC. NCHS, 2010a).

The CDC, National Center for Health Statistics (NCHS) conducts the NHANES program which consists of a series of cross-sectional surveys with a nationally representative sample of the United States (US) civilian non-institutionalized population. NHANES use a complex, multistage probability design to identify possible survey participants (CDC. NCHS, 2010c).

\section{SAMPLE WITH SETTING}

This study used the adolescent sub-sample, aged 12- to 19-year-olds, from the original NHANES data sets from 1999-2004 who had whole body DXA data and BMI measurement. Subjects for the NHANES study were selected from the civilian noninstitutionalized US population based on a complex, multistage probability design with oversampling of select subgroups (CDC. NCHS, 2010c). Subgroups that were oversampled included low-income, adolescents 12- to 19-year-olds, persons aged 60 years and older, African Americans, and Mexican Americans. Oversampling was used to improve the precision of statistic estimates for these groups (CDC. NCHS, 2010a). The current study examined the subpopulation of 5416 adolescents (12- to 19-year-olds) who had BMI measurement and whole body DXA with validated data between 1999 and 2004. The number of adolescents with DXA available from the 1999-2000, 2001-2002, and 2003-2004 NHANES were 1258, 2147, and 2011 respectively (CDC. NCHS, 2010a). These three NHANES data sets provided a large and robust sample of 5416 adolescents for the current study.

\section{INCLUSION CRITERIA}

In the original NHANES study, whole body DXA scans were conducted on subjects who were aged 8 years and older (CDC. NCHS, 2010b). This study included all 
subjects from the original NHANES data sets 1999-2004 with whole body DXA data between the ages of 12 and 19 years at the time of examination. This study also required that each participant in this age group with whole body DXA data have BMI measured.

\section{EXCLUSION CRITERIA}

Exclusion criteria for the current study were original NHANES survey participants younger than 12 years of age or older than 19 years of age. Also, original NHANES survey participant who did not have DXA or BMI data were excluded from the current study. In the original NHANES study (CDC. NCHS, 2010b), participants were excluded from DXA testing if they:

- were pregnant or self-reported being pregnant

- reported use of radiographic contrast material (barium) in the past 7 days

- reported use of nuclear medicine studies in the past 3 days

- weighed over 300 pounds (weight limit of DXA densitometer)

- were taller than 6'5" (length of DXA scanning area)

During 1999 there were concerns about reporting pregnancy test results for minors, thus all female 8- to 17-year-olds were excluded from DXA testing. This concern was resolved before 2000, and DXA testing was initiated in 2000 for non-pregnant females over 8 years of age (CDC. NCHS, 2010a).

\section{INSTRUMENTS WITH PROCEDURES}

Instruments used in this study were exclusive to those used in the Continuous NHANES. The procedures for NHANES data collected are detailed in the documentation at the CDC, NHANES website (CDC. NCHS, 2010b, 2010c). In summary, households selected for the survey were sent letters explaining the purpose of the survey and outlining the confidentiality of their responses if they elect to participate in the survey. Identified individuals were interviewed in their home initially to determine eligibility, obtain consent and answer specific questionnaires. Participants are asked after the household interview to participate in the health assessment component. The health assessment component was conducted in one of three mobile examination centers (MECs). The MEC used standardized techniques and equipment to collect high-quality data. The surveys were conducted over a two year period. Data were compiled and released in two year cycles in public-use data files (CDC. NCHS, 2010a). 


\section{Demographics}

Households selected for inclusion in the NHANES sample were sent a letter informing the occupants that a NHANES interviewer would visit their home. The interviewer, upon arrival at the household, verified if the occupants had received the announcement letter and provided a copy of the letter to the occupants. The interviewer explained the household questionnaires, informed participants of their rights in the survey and provided assurances about the confidentiality of the survey data. The household interview was comprised of three interview questionnaires: the Screener interview, the Sample Person interview and the Family interview. The Screener interview determined if the household occupants were eligible to participate and the demographic data used in this study was obtained through the Screener interview. If eligible participants were identified in the Screener interviews and consented to participate in the study, the other interviews were conducted. Household interviews for participants under 16 years of age were conducted with a proxy, usually a parent. Participants under 16 years of age were allowed to self-report, if no one living in the household was over the age of 16. Participants were asked to sign separate consent forms agreeing to participate in the household interview portion of the survey and in the health assessment portion of the survey.

The demographic variables for this study were gathered during the Screener interview. Age was calculated in months based on the reported date of birth of the participant and the date of the examination at the MEC. Gender and race/ethnicity were self-reported. Data were collected using the Computer Assisted Personal Interviewing (CAPI) system to increase data collection accuracy. This system prompted the interviewer to complete each field and notified the interviewer if an entry was outside of accepted range values. For the purpose of the current study, the following demographic variables from the data sets were included in the analysis: gender (male or female), exam age in months, and race/ethnicity based on the RIDRETH2 variable (Caucasian, African American, Mexican American, Other Race, or Other Hispanic).

\section{Dual Energy X-ray Absorptiometry (DXA)}

Whole body DXA scans were obtained in the MEC as part of the health assessment (CDC. NCHS, 2010b). The DXA scans provided the LLE BMC measured in gm. The current study hypothesized that greater BMI will be positively associated with greater BMC. The BMC of the LE was selected as the location of interest because the bones of the LE support the individual's weight during weight bearing and would likely be affected by a greater BMI. Therefore, BMC of the lower extremities was selected as the best DXA measurements to examine to determine the relationship of BMI on bone status. The BMC of LLE was chosen as the dependent variable to ensure consistency.

Survey participants were asked to remove all metal objects from their body including jewelry, belts, snaps and underwire bras to prevent interference with the scan. Each of the three MECs was equipped with a Hologic QDR 4500A fan-beam bone densitometer (Hologic, Inc., Bedford, Massachusetts) using Hologic software version 
8.26:a3. Certified radiology technologists performed all scans following the details of the DXA examination protocol. The technologists positioned the survey participants in the DXA scanning area in a supine position with toes pointing together and secured with Velcro strap to reduce movement. The whole body DXA scans required only three minutes for the three passes of the overhead scanning arm. Each DXA scan was analyzed and reviewed by the NHANES quality control at the University of California, San Francisco (UCSF), Department of Radiology using standard radiologic techniques and study-specific protocols. Hologic Discovery software, version 12.1, was used to analyze the scans (CDC. NCHS, 2010b).

Each of the three MECs followed an elaborate quality control schedule (CDC. NCHS, 2010b) of scanning with phantoms and with air to ensure accurate calibration of the densitometers as well as cross-calibration between the densitometers. Daily spine phantom scans occurred in each MEC. Spine, whole body and tissue step phantoms were scanned weekly or more. Air, without a phantom, scans of the whole body scan area were performed to monitor the uniformity of the entire scan area. A series of phantoms were circulated between the three MEC densitometers in addition to the MEC specific phantoms for quality control scans. The UCSF quality control team monitored the data from these quality control scans to ensure the densitometers performed within established parameters. The UCSF quality control group determined no adjustments of the participants' data were warranted since the magnitude for the correction factor was insignificant (CDC. NCHS, 2010b).

Prior research with the QDR 4500A densitometer (Schoeller et al., 2005) indicated that the algorithm underestimates fat mass and overestimates lean mass by $5 \%$. Therefore, participant results were adjusted by UCSF adding $5 \%$ to the fat mass and reducing lean mass by the same amount for each region.

The quality control group at UCSF found some scans to have missing or invalid data in some of the DXA data fields. This situation occurred due to a number of reasons including objects in the scanning field which were not removed, non-removable objects in the scanning field (for example, internal pins for fracture repair), excessive truncal adiposity causing x-ray noise, arm and leg overlap, body parts out of scan field, positioning errors, missing limbs, participant motion, and unknown artifacts. The UCSF quality control performed five multiple imputations of the DXA data using the SAScallable imputation and variance estimation software, IVEware. The IVEware used the sequential regression imputation method to produce an estimate for the missing or invalid data fields from the DXA scan. Each participant's scan had five imputations of the data from the scan. The data fields for the five imputations were the same if the participant had no missing or invalid data fields on the DXA scan. The values in the data field were different among the imputations if there was any missing or invalid value in that data field (CDC. NCHS, 2010b). 


\section{Body Mass Index (BMI)}

Anthropometry measurements for BMI were obtained as a part of the health assessment in the MEC (CDC. NCHS, 2010b). These measurements were gathered by an examiner and verified by a recorder. Survey participants were asked to wear the standard MEC examination clothing, which included a disposable shirt, pants and slippers. If subject wore their own clothes ( 3 of 5416), the examiner entered a clothing code in the data file. If they wore a non-removable medical appliance ( 3 of 5416), the examiner entered a medical appliance code. Weight was determined when the participant stood on the digital scale that was connected directly to the Integrated Survey Information System (ISIS). Weight was measured to hundredth of a kilogram. The digital scale was calibrated with a set of weights daily, at the beginning of stand (set-up at a new location), at the middle of a stand (midpoint of stay at a given location), and at the end of a stand (prior to moving from a location). There was also a manual method to enter data into ISIS, in the event the data from the digital scale failed to import directly into ISIS. There were portable scales available if the digital scale was malfunctioning. Height was measured with an electronic stadiometer that was also connected to the ISIS. Height was measured to a tenth of a centimeter. If the survey participant did not wear the examination slippers, but wore their own shoes, then the examiner measured the heel of the shoe and entered the measurement into the data file. Height was corrected by subtracting the heel height of the shoes. The stadiometer was calibrated in a similar fashion as the scale, except instead of calibrated weights, a calibrated metal rod was used. Calibration of stadiometer occurred at the start of the stand and weekly. There was a steel tape measure adhered to the wall next to the stadiometer for use by the examiner, in the event the electronic stadiometer was malfunctioning. The data could be manually entered into the ISIS, if needed (CDC. NCHS, 2010b).

The 2000 CDC growth charts BMI (CDC, 2010) for age for girls and boys 2- to 19-year-olds were used to classify the adolescents as either (1) underweight as less than the $5^{\text {th }}$ percentile, (2) healthy weight as greater than or equal to the $5^{\text {th }}$ percentile to less than the $85^{\text {th }}$ percentile, (3) overweight as greater than or equal to the $85^{\text {th }}$ percentile to less than the $95^{\text {th }}$ percentile, or (4) obese as greater than or equal to the $95^{\text {th }}$ percentile. These are the same definitions as adopted in the National Health Statistics Report (Ogden \& Flegal, 2010). The classification of the adolescents according to BMI for age was only used in the sample description analysis for this study and was not part of NHANES.

\section{PROTECTION OF HUMAN SUBJECTS}

This current study received approval from the University's Institutional Review Board (Appendix). The data for this current study are from the de-identified public-use files available on the NCHS NHANES website (CDC. NCHS, 2010a). The original NHANES 1999-2004 procedures were approved by the NCHS Ethics Review Board. Written informed consent was obtained from all participants and/or guardians. Participants who were 16 or 17 year-olds gave their assent, while a parent or guardian provided consent. Participants who were 18 or 19 years of age provided consent. Separate consent forms were obtained for the household interview and the health 
assessment in the MEC. Risks to human subjects were minimized. Self-reported pregnant females were excluded from testing and other females were tested for pregnancy prior to scanning despite the low radiation exposure from the densitometer (CDC. NCHS, 2010b).

\section{DATA ANALYSIS}

Data analyses were performed using SAS software version 9.2. The public-release data files contain de-identified data in XPT files. The nine XPT files were transferred into a SAS library as nine SAS data sets. The nine data sets were imported to SAS to merge and append the data sets into one set of data. Since NHANES is based on a complex, multistage probability design, six-year sampling weights were needed for the analysis of the three biennial data sets. The six-year sampling weights were calculated from the twoyear and four-year sampling weights for MEC, since BMI and DXA data were gathered from the MEC. The complex, multistage probability design of NHANES is clustered around population sampling units (PSU) with stratification of the sampled population along selected stratum. The six-year sampling weights along with the clustering PSU and stratification strata were used in the analysis of survey data to get proper survey regression estimates with standard errors and survey means as outlined in the NHANES analytic guidelines (CDC. NCHS, 2010b). Frequency distributions were obtained for gender and race/ethnicity along with BMI distribution for underweight, normal weight, overweight, and obese. Descriptive statistics were performed using survey means to characterize the variables of interest including BMI, weight $(\mathrm{kg})$, height $(\mathrm{cm})$, and age at scan (months).

When comparing the DXA results of children and adolescents, the International Society of Clinical Densitometry guidelines (Gordon, et al., 2008) recommend using a standard reference for comparison. Height is an acceptable standard when comparing DXA results of adolescents in accordance with the International Society of Clinical Densitometry guidelines. Height was readily available in this study for use in comparing these DXA results, since height is a component of BMI. Height was used in every regression comparing the adolescents' DXA results, since BMI was examined in every regression.

Survey regression analysis with graphing of data was performed to analyze the functional form of the relationship of LLE BMC on BMI five times, once for each imputation of DXA data. Significance level was set at $5 \%(\alpha=0.05)$ for all tests. The total sample was analyzed using simple linear regression of LLE BMC on BMI by domains based on the demographic groups of gender, race/ethnicity, age category, and then combinations of these groups. See Table 3.1, Table 3.2, and Table 3.3 for the lists of the analyzed domains with their levels (order of analysis) and names. Survey regression was performed initially for the entire sample of adolescents as a single group in one domain at level I to determine if a relationship existed and obtained regression coefficient estimates of LLE BMC on BMI. In addition to the usual assumptions necessary for regression analysis using the ordinary least-squares method, an explicit assumption for analysis of covariance is that of homogeneity of slopes. Analysis of covariance cannot proceed 
Table 3.1. Level II domains as derived from their demographic groups $(\mathrm{N}=5416)$.

\begin{tabular}{llc}
\hline Demographic Group & \multicolumn{1}{c}{ Domain } & $\mathrm{n}$ \\
\hline Gender & Male & 3235 \\
& Female & 2181 \\
Race/Ethnicity & Caucasian & 1480 \\
& African American & 1737 \\
& Mexican American & 1841 \\
& Other Races & 139 \\
Age & Other Hispanic & 219 \\
& 12- to 13-year-olds & 1400 \\
& $14-$ to 15-year-olds & 1287 \\
& 16 - to 17-year-olds & 1326 \\
\hline
\end{tabular}


Table 3.2. Level III domains permutations of two of the three demographic groups $(\mathrm{N}=5416)$.

\begin{tabular}{|c|c|c|}
\hline \multirow{11}{*}{$\begin{array}{l}\text { Demographic Group } \\
\text { Gender with Race/Ethnicity }\end{array}$} & Domain & $\mathrm{n}$ \\
\hline & Male Caucasian & 855 \\
\hline & Male African American & 1058 \\
\hline & Male Mexican American & 1114 \\
\hline & Male Other Races & 79 \\
\hline & Male Other Hispanic & 129 \\
\hline & Female Caucasian & 625 \\
\hline & Female African American & 679 \\
\hline & Female Mexican American & 727 \\
\hline & Female Other Races & 60 \\
\hline & Female Other Hispanic & 90 \\
\hline \multirow[t]{8}{*}{ Gender with Age } & Male 12- to 13 -year-olds & 842 \\
\hline & Male 14- to 15-year-olds & 772 \\
\hline & Male 16- to 17 -year-olds & 859 \\
\hline & Male 18- to 19-year-olds & 762 \\
\hline & Female 12 - to 13 -year-olds & 558 \\
\hline & Female 14 - to 15 -year-olds & 515 \\
\hline & Female 16 - to 17 -year-olds & 467 \\
\hline & Female 18 - to 19 -year-olds & 641 \\
\hline \multirow[t]{20}{*}{ Race/Ethnicity with Age } & CA12- to 13-year-olds & 367 \\
\hline & CA 14- to 15 -year-olds & 355 \\
\hline & CA16- to 17-year-olds & 368 \\
\hline & CA 18 - to 19 -year-olds & 390 \\
\hline & AA 12 - to 13 -year-olds & 468 \\
\hline & AA 14 - to 15 -year-olds & 424 \\
\hline & AA 16 - to 17 -year-olds & 437 \\
\hline & AA 18 - to 19 -year-olds & 408 \\
\hline & MA 12- to 13-year-olds & 472 \\
\hline & MA 14- to 15-year-olds & 430 \\
\hline & MA 16 - to 17 -year-olds & 434 \\
\hline & MA 18 - to 19 -year-olds & 505 \\
\hline & OR 12- to 13-year-olds & 30 \\
\hline & OR 14- to 15 -year-olds & 30 \\
\hline & OR 16- to 17 -year-olds & 30 \\
\hline & OR 18- to 19 -year-olds & 49 \\
\hline & OH 12- to 13 -year-olds & 63 \\
\hline & OH 14 - to 15 -year-olds & 48 \\
\hline & OH 16 - to 17 -year-olds & 57 \\
\hline & OH 18 - to 19 -year-olds & 51 \\
\hline
\end{tabular}

Notes: $\mathrm{CA}=$ Caucasian, $\mathrm{AA}=\mathrm{A}$ frican American $\mathrm{MA}=$ Mexican American, $\mathrm{OR}=\mathrm{Other}$ Race, $\mathrm{OH}=$ Other Hispanic. 
Table 3.3. Level IV domains permutations from all three of the demographic groups $(\mathrm{N}=5416)$.

\begin{tabular}{|c|c|c|}
\hline \multirow{41}{*}{$\begin{array}{l}\text { Demographic Group } \\
\text { Gender with Race/Ethnicity and Age }\end{array}$} & Domain & $\mathrm{n}$ \\
\hline & Male CA 12- to 13-year-olds & 217 \\
\hline & Male CA 14- to 15-year-olds & 208 \\
\hline & Male CA 16- to 17-year-olds & 219 \\
\hline & Male CA 18- to 19-year-olds & 211 \\
\hline & Male AA 12 - to 13 -year-olds & 278 \\
\hline & Male AA 14- to 15-year-olds & 258 \\
\hline & Male AA 16- to 17-year-olds & 293 \\
\hline & Male AA 18 - to 19 -year-olds & 229 \\
\hline & Male MA 12- to 13-year-olds & 297 \\
\hline & Male MA 14- to 15-year-olds & 258 \\
\hline & Male MA 16- to 17-year-olds & 291 \\
\hline & Male MA 18- to 19-year-olds & 268 \\
\hline & Male OR 12- to 13-year-olds & 13 \\
\hline & Male OR 14- to 15-year-olds & 18 \\
\hline & Male OR 16- to 17 -year-olds & 18 \\
\hline & Male OR 18- to 19-year-olds & 30 \\
\hline & Male $\mathrm{OH} 12$ - to 13 -year-olds & 37 \\
\hline & Male $\mathrm{OH} 14$ - to 15 -year-olds & 30 \\
\hline & Male $\mathrm{OH} 16$ - to 17 -year-olds & 38 \\
\hline & Male OH 18 - to 19 -year-olds & 24 \\
\hline & Female CA 12 - to 13 -year-olds & 150 \\
\hline & Female CA 14 - to 15 -year-olds & 147 \\
\hline & Female CA 16 - to 17 -year-olds & 149 \\
\hline & Female CA 18 - to 19 -year-olds & 179 \\
\hline & Female AA 12 - to 13 -year-olds & 190 \\
\hline & Female AA 14 - to 15 -year-olds & 166 \\
\hline & Female AA 16 - to 17 -year-olds & 144 \\
\hline & Female AA 18 - to 19 -year-olds & 179 \\
\hline & Female MA 12- to 13-year-olds & 175 \\
\hline & Female MA 14 - to 15 -year-olds & 172 \\
\hline & Female MA 16- to 17 -year-olds & 143 \\
\hline & Female MA 18 - to 19 -year-olds & 237 \\
\hline & Female OR 12 - to 13 -year-olds & 17 \\
\hline & Female OR 14 - to 15 -year-olds & 12 \\
\hline & Female OR 16 - to 17 -year-olds & 12 \\
\hline & Female OR 18 - to 19 -year-olds & 19 \\
\hline & Female $\mathrm{OH} 12$ - to 13 -year-olds & 26 \\
\hline & Female $\mathrm{OH} 14$ - to 15 -year-olds & 18 \\
\hline & Female $\mathrm{OH} 16$ - to 17 -year-olds & 19 \\
\hline & Female $\mathrm{OH} 18$ - to 19 -year-olds & 27 \\
\hline
\end{tabular}

Notes: $\mathrm{CA}=$ Caucasian, $\mathrm{AA}=\mathrm{African}$ American $\mathrm{MA}=$ Mexican American, $\mathrm{OR}=\mathrm{Other}$ Race, $\mathrm{OH}=$ Other Hispanic. 
without homogeneity of slopes. Without homogeneity of slopes, data could not be pooled and remained stratified by its levels of analysis.

Then, the level II domains were analyzed. The two gender domains (Male and Female) were examined, followed by the five race/ethnicity domains (Caucasian, African American, Mexican American, Other Hispanic, and Other Race) and the four age category domains (12- to 13-year-olds, 14- to 15-year-olds, 16- to 17-year-olds, and 18to 19-year-olds). These age categories were chosen to be consistent with a previous DXA NHANES reference study.(Kelly, Wilson, \& Heymsfield, 2009) The estimated regression coefficients were compared to the $95 \%$ confidence interval (CI) of the estimates from similar groups within level II domains to determine if the slopes were homogeneous and therefore, if the groups should be combined for analysis of covariance.

Next, the analysis examined survey regression level III domains based on permutations from two of three demographic groups. The 38 domains developed from the permutations from two groups were examined: gender with race/ethnicity (10); gender with age category (8); and race/ethnicity with age category (20). Again, the resulting estimates of slopes were compared within similar groups using the $95 \% \mathrm{CI}$ to determine if the domains from similar groups could be pooled.

Finally, each level IV domain from the permutations of the three demographic groups of gender, race/ethnicity, and age category were analyzed. This resulted in 40 different domains at level IV. The estimates of slopes from similar groups were compared using the $95 \%$ CI to determine if the domains from similar groups could be pooled. Thus, the data for a total of $90(1+11+38+40)$ domains with five imputations of data for each domain were analyzed resulting in 450 estimated regression coefficients (slopes) with their SEs, associated intercepts with their SEs, $p$ values and 95\% CIs.

Each domains' five estimated regression coefficients (slopes) with their SEs, associated intercepts with their SEs, probability values and 95\% CIs for each imputation were then averaged as outlined in the NHANES Technical Documentation (CDC. NCHS, 2010b). The intercepts and slopes for the five imputations were averaged using the arithmetic mean to produce a slope and an intercept for each domain. Computation of the SE for the respective slope and the SE for the respective intercept involved several steps. Initially, each SE for the slope was squared obtaining its variance. The within-imputation variance $(\mathrm{W})$ was calculated using the arithmetic mean of the five variances. The between-imputation variance (B) was calculated, which was the sample variance for the five individual slopes.

$$
B=\sum_{n=1}^{5}\left(\text { slope }_{n}-\text { mean slope }\right)^{2} /(5-1)
$$

The total variance $(\mathrm{T})$ combined the between-imputation and the withinimputation variances.

$$
T=W+\frac{(5+1)}{5} B
$$


The SE for the slope was the square root of T. This process was repeated for each slope and intercept for the estimated regression lines from the 18 domains with different imputed data. The more conservative $95 \%$ confidence interval of the slope was calculated using the formula; slope $\pm 1.96^{*}$ (combined SE). 


\section{CHAPTER 4. MANUSCRIPT}

\section{INTRODUCTION}

This study was undertaken to explore the relationship between body mass index (BMI) and the dual energy X-ray absorptiometry (DXA) measurement of bone mineral content (BMC) in adolescents across the spectrum of weight. Data from the 1999-2004 Continuous National Health Assessment and Nutritional Examination Surveys (NHANES) were used to provide a large nationally representative group of adolescents.

Research regarding the relationship of obesity to BMC has yielded equivocal results. In adults, increased BMI enhanced bone mass (Reid, 2002). Similarly, several cross-sectional studies in youth support a positive association between BMI and bone density (Cobayashi, et al., 2005; Leonard, et al., 2004) or BMC (Braillon, et al., 2002; Ellis, et al., 2003; Leonard, et al., 2004). Obese children had higher BMC compared with leaner children, even when adjusted for height, age, gender, and ethnicity (Ellis, et al., 2003). Additionally, weight changes in obese, female adolescents were strongly related to changes in BMC and bone mineral density (Rourke, et al., 2003).

In contrast, Goulding et al. (2000) found obese and overweight children and adolescents had lower than predicted bone mass and bone area for their size. These findings were confirmed in a subsequent study (Goulding, et al., 2002) suggesting that overweight children and adolescents do not increase spinal BMC to adequately compensate for their increased weight. Similarly, De Schepper, Van den Broeck, and Jonckheer (1995) found that older obese children and young obese adolescents had normal, not greater, spine bone mineral density. Other researchers concluded in a study with 6- to 18-year-olds (Ackerman, et al., 2006) that individuals with greater fat mass will have lower BMC than individuals with greater lean mass.

In the few studies (Fernandez-Garcia, et al., 2009; Galusca, et al., 2008) that have examining BMC in healthy low weight adolescents and young adults, there was no controversy. The results were the same; BMC was positively associated with BMI. Adolescents with low BMI had low BMC and low bone density.

These studies have examined bone mineral density and BMC in different regions of the body, making comparisons across studies difficult. The majority of the studies had relatively small sample sizes and the studies were limited in the range of BMI examined. It is unclear what the true effect of increased BMI has on BMC in adolescents, despite the number of studies examining the effects of increased mass on BMC. This study explored the functional form of the relationship between left lower extremity (LLE) BMC and BMI across the entire spectrum of weight in a large nationally representative group of adolescents. 


\section{METHODS}

This descriptive study used secondary data from the publically accessible, crosssectional survey files of the 1999-2004 NHANES that contained whole body DXA data as well as BMI calculations. The Centers for Disease Control and Prevention (CDC), National Center for Health Statistics (NCHS) conducts the NHANES program which consists of a series of cross-sectional surveys with a nationally representative sample of the United States (US) civilian, non-institutionalized population. NHANES use a complex, multistage probability design with oversampling of select groups including low-income, adolescents 12- to 19-year-olds, persons aged 60 years and older, African Americans, and Mexican Americans (CDC. NCHS, 2010c). This study included the adolescent sample from the original 1999-2004 NHANES data sets, who were 12- to 19year-olds at the time of examination and had whole body DXA and BMI data. Participants were excluded from DXA testing in the original surveys if they (1) were pregnant, (2) reported recent exposure to radiographic contrast material (barium) or nuclear medicine studies, or (3) exceeded height or weight limits of the DXA scanner (CDC. NCHS, 2010b).

The procedures for the collection of NHANES data are detailed in the documentation at the CDC, NHANES website (CDC. NCHS, 2010b, 2010c). The demographic variables were gathered during the Screener interview as part of the household interview. Participants were classified as Caucasian, African American, Mexican American, Other Race, or Other Hispanic based on self-reported race/ethnicity. Gender and date of birth were also self-reported.

Whole body DXA scans were obtained in the mobile examination center (MEC) as part of the health assessment (CDC. NCHS, 2010b). Survey participants were asked to remove all metal objects from their body to prevent interference with the scan. Each MEC was equipped with a Hologic QDR 4500A fan-beam bone densitometer (Hologic, Inc., Bedford, Massachusetts), using Hologic data acquisition software version 8.26:a3. Certified radiology technologists performed all scans following the details of the DXA examination protocol. Each DXA scan was analyzed and reviewed by the NHANES quality control group at the University of California, San Francisco (UCSF), Department of Radiology using standard radiologic techniques and study-specific protocols. Hologic Discovery software, version 12.1, was used to analyze the scans (CDC. NCHS, 2010b). Each of the three MECs followed an elaborate quality control schedule (CDC. NCHS, 2010b), which included scanning of phantoms and air to ensure accurate calibration of the densitometers as well as cross-calibration between the densitometers. Prior research with the QDR 4500A densitometer (Schoeller, et al., 2005) indicated that the analysis software algorithm underestimates fat mass and overestimates lean mass by $5 \%$. Therefore, participant results were adjusted by UCSF quality control group adding $5 \%$ to the fat mass and reducing lean mass by the same amount for each region.

The current study hypothesized that greater BMI will be positively associated with greater BMC. The BMC of the lower extremity (LE) was selected as the location of interest because the bones of the LE support the individual's weight during weight bearing and would likely be affected by a greater BMI. Therefore, BMC of the lower 
extremities was selected as the best DXA measurements to examine to determine the relationship of BMI on bone status. The BMC of LLE was chosen as the dependent variable to ensure consistency.

The quality control group at UCSF found less than 1\% (43 of 5416) of the adolescent DXA scans had missing or invalid data in the LLE bone data field. Missing or invalid data were due to objects in the scanning field which were not removed, nonremovable objects in the scanning field (for example, internal pins for fracture repair), arm and leg overlap, body parts out of scan field, positioning errors, missing limbs, participant motion, and unknown artifacts. To produce an estimate for the missing or invalid data fields from the DXA scan, the UCSF quality control group used the SAScallable imputation and variance estimation software, IVEware, which uses the sequential regression imputation method, to calculate five imputations of the DXA data. Therefore, each participant had five imputations of their scan. The five imputations were the same if the participant had no missing or invalid data fields on the DXA scan (CDC. NCHS, 2010a).

Anthropometric measurements for BMI were obtained using calibrated digital scales and stadiometer in the MEC (CDC. NCHS, 2010b). The digital scales and stadiometer were calibrated routinely with weights and metal rods of known weight and height, respectively. Survey participants were asked to wear the standard MEC examination clothing, which included a disposable shirt, pants and slippers. If they wore their own clothes ( 3 of 5416), the examiner entered a clothing code in the data file. If they wore a non-removable medical appliance ( 3 of 5416), the examiner entered a medical appliance code. Weight was determined when the participant stood on the digital scale and was measured to hundredth of a kilogram. Height was measured to a tenth of a centimeter using an electronic stadiometer with the participant wearing the examination slippers or their own shoes. If participants wore their own shoes, the measured height was corrected by subtracting the heel height of the shoes (CDC. NCHS, 2010b). The 2000 CDC growth charts BMI (CDC, 2010) were used to classify the adolescents as either (1) underweight (less than the $5^{\text {th }}$ percentile), (2) healthy weight $\left(5^{\text {th }}\right.$ percentile to less than $85^{\text {th }}$ percentile), (3) overweight ( $85^{\text {th }}$ percentile to less than $95^{\text {th }}$ percentile), or (4) obese $\left(95^{\text {th }}\right.$ percentile or higher) based on definitions adopted in the National Health Statistics Report (Ogden \& Flegal, 2010).

This current study received approval from The University of Tennessee Health Science Center Institutional Review Board and used the de-identified public-use files available on the NCHS NHANES website (CDC. NCHS, 2010a). The original NHANES 1999-2004 procedures were approved by the NCHS Ethics Review Board with written informed consent obtained from participants and/or guardians. Additionally participants who were 16 or 17 year-olds provided their assent. Risks to human subjects were minimized by excluding pregnant females from DXA scanning (CDC. NCHS, 2010b). 


\section{DATA ANALYSIS}

Data analyses were performed using survey procedures in SAS software version 9.2. Six-year sampling weights were needed for the analysis of the three biennial data sets, since NHANES is based on a complex, multistage probability design based on the US population. The six-year sampling weights were calculated from the two-year and four-year sampling weights based on participants who were examined in the MEC, since BMI and DXA data were gathered from the MEC. The complex, multistage probability design of NHANES is clustered around population sampling units with stratification of the sampled population along selected stratum. The six-year sampling weights along with the clustering population sampling units and stratification strata were used in the analysis of the survey data to obtain proper survey regression estimates with their associated standard errors (SE) and survey means as outlined in the NHANES analytic guidelines (CDC. NCHS, 2010b). Frequency distributions were obtained for gender and race/ethnicity along with BMI distribution for underweight, normal weight, overweight, and obese. Descriptive statistics were performed using survey means to characterize the variables of interest including BMI, weight $(\mathrm{kg})$, height $(\mathrm{cm})$, and age at scan (months).

When comparing the DXA results of children and adolescents, the International Society of Clinical Densitometry guidelines (Gordon, et al., 2008) recommend using a standard reference for comparison. Height is an acceptable standard when comparing DXA results of adolescents in accordance with the International Society of Clinical Densitometry guidelines. Height was readily available in this study for use in comparing these DXA results, since height is a component of BMI. Height was used in every regression comparing the adolescents' DXA results, since BMI was examined in every regression.

Survey regression analysis with graphing of data was performed to analyze the functional form of the relationship of LLE BMC on BMI five times, once for each imputation of DXA data. Significance level was set at $5 \%(\alpha=0.05)$ for all tests. The total sample was analyzed using simple linear regression of LLE BMC on BMI by domains based on the demographic groups of gender, race/ethnicity, age category, and then combinations of these groups. See Table 4.1, Table 4.2, and Table 4.3 for the lists of the analyzed domains with their levels (order of analysis) and names. Survey regression was performed initially for the entire sample of adolescents as a single group in one domain at level I to determine if a relationship existed and obtain regression coefficient estimates of LLE BMC on BMI. In addition to the usual assumptions necessary for regression analysis using the ordinary least-squares method, an explicit assumption for analysis of covariance is that of homogeneity of slopes. Analysis of covariance cannot proceed without homogeneity of slopes. Without homogeneity of slopes, data could not be pooled and remained stratified by its levels of analysis.

Then, the level II domains were analyzed. The two gender domains (Male and Female) were examined, followed by the five race/ethnicity domains (Caucasian, African American, Mexican American, Other Hispanic, and Other Race) and the four age category domains (12- to 13-year-olds, 14- to 15-year-olds, 16- to 17-year-olds, and 18to 19-year-olds). These age categories were chosen to be consistent with a previous DXA 
Table 4.1. Level II domains as derived from their demographic groups $(\mathrm{N}=5416)$.

\begin{tabular}{llc}
\hline Demographic Group & \multicolumn{1}{c}{ Domain } & $\mathrm{n}$ \\
\hline Gender & Male & 3235 \\
& Female & 2181 \\
Race/Ethnicity & Caucasian & 1480 \\
& African American & 1737 \\
& Mexican American & 1841 \\
& Other Races & 139 \\
Age & Other Hispanic & 219 \\
& 12- to 13-year-olds & 1400 \\
& $14-$ to 15-year-olds & 1287 \\
& 16 - to 17-year-olds & 1326 \\
\hline
\end{tabular}


Table 4.2. Level III domains permutations of two of the three demographic groups $(\mathrm{N}=5416)$.

\begin{tabular}{llc}
\hline Demographic Group & Domain & $\mathrm{n}$ \\
\hline Gender with Race/Ethnicity & Male Caucasian & 855 \\
& Male African American & 1058 \\
& Male Mexican American & 1114 \\
Male Other Races & 79 \\
Male Other Hispanic & 129 \\
Female Caucasian & 625 \\
Female African American & 679 \\
Female Mexican American & 727 \\
Female Other Races & 60 \\
Female Other Hispanic & 90 \\
& Male 12- to 13-year-olds & 842 \\
Male 14- to 15-year-olds & 772 \\
Male 16- to 17-year-olds & 859 \\
Male 18- to 19-year-olds & 762 \\
Female 12- to 13-year-olds & 558 \\
Fende 14- to 15-year-olds & 515 \\
Female 16- to 17-year-olds & 467 \\
Female 18- to 19-year-olds & 641 \\
CA12- to 13-year-olds & 367 \\
CA 14- to 15-year-olds & 355 \\
CA16- to 17-year-olds & 368 \\
CA 18- to 19-year-olds & 390 \\
AA 12- to 13-year-olds & 468 \\
AA 14- to 15-year-olds & 424 \\
AA 16- to 17-year-olds & 437 \\
AA 18- to 19-year-olds & 408 \\
MA 12- to 13-year-olds & 472 \\
MA 14- to 15-year-olds & 430 \\
MA 16- to 17-year-olds & 434 \\
MA 18- to 19-year-olds & 505 \\
OR 12- to 13-year-olds & 30 \\
OR 14- to 15-year-olds & 30 \\
OR 16- to 17-year-olds & 30 \\
OR 18- to 19-year-olds & 49 \\
OH 12- to 13-year-olds & 63 \\
OH 14- to 15-year-olds & 48 \\
OH 16- to 17-year-olds & 57 \\
OH 18- to 19-year-olds & 51 \\
\hline & & \\
& &
\end{tabular}

Notes: $\mathrm{CA}=$ Caucasian, $\mathrm{AA}=\mathrm{A}$ frican American $\mathrm{MA}=$ Mexican American, $\mathrm{OR}=\mathrm{Other}$ Race, $\mathrm{OH}=$ Other Hispanic. 
Table 4.3. Level IV domains permutations from all three of the demographic groups $(\mathrm{N}=5416)$.

\begin{tabular}{|c|c|c|}
\hline Demographic Group & Domain & $\mathrm{n}$ \\
\hline \multirow[t]{40}{*}{ Gender with Race/Ethnicity and Age } & Male CA 12- to 13-year-olds & 217 \\
\hline & Male CA 14- to 15 -year-olds & 208 \\
\hline & Male CA 16- to 17 -year-olds & 219 \\
\hline & Male CA 18- to 19-year-olds & 211 \\
\hline & Male AA 12 - to 13 -year-olds & 278 \\
\hline & Male AA 14- to 15-year-olds & 258 \\
\hline & Male AA 16- to 17-year-olds & 293 \\
\hline & Male AA 18 - to 19 -year-olds & 229 \\
\hline & Male MA 12- to 13-year-olds & 297 \\
\hline & Male MA 14- to 15-year-olds & 258 \\
\hline & Male MA 16- to 17-year-olds & 291 \\
\hline & Male MA 18- to 19-year-olds & 268 \\
\hline & Male OR 12- to 13-year-olds & 13 \\
\hline & Male OR 14- to 15-year-olds & 18 \\
\hline & Male OR 16- to 17 -year-olds & 18 \\
\hline & Male OR 18- to 19-year-olds & 30 \\
\hline & Male OH 12-to 13-year-olds & 37 \\
\hline & Male $\mathrm{OH} 14$ - to 15 -year-olds & 30 \\
\hline & Male $\mathrm{OH} 16$ - to 17 -year-olds & 38 \\
\hline & Male OH 18- to 19-year-olds & 24 \\
\hline & Female CA 12 - to 13 -year-olds & 150 \\
\hline & Female CA 14- to 15 -year-olds & 147 \\
\hline & Female CA 16 - to 17 -year-olds & 149 \\
\hline & Female CA 18 - to 19 -year-olds & 179 \\
\hline & Female AA 12 - to 13 -year-olds & 190 \\
\hline & Female AA 14 - to 15 -year-olds & 166 \\
\hline & Female AA 16 - to 17 -year-olds & 144 \\
\hline & Female AA 18 - to 19 -year-olds & 179 \\
\hline & Female MA 12- to 13-year-olds & 175 \\
\hline & Female MA 14 - to 15 -year-olds & 172 \\
\hline & Female MA 16- to 17 -year-olds & 143 \\
\hline & Female MA 18 - to 19 -year-olds & 237 \\
\hline & Female OR 12- to 13 -year-olds & 17 \\
\hline & Female OR 14- to 15 -year-olds & 12 \\
\hline & Female OR 16 - to 17 -year-olds & 12 \\
\hline & Female OR 18- to 19 -year-olds & 19 \\
\hline & Female $\mathrm{OH} 12$ - to 13 -year-olds & 26 \\
\hline & Female $\mathrm{OH} 14$ - to 15 -year-olds & 18 \\
\hline & Female OH 16- to 17 -year-olds & 19 \\
\hline & Female $\mathrm{OH} 18$ - to 19 -year-olds & 27 \\
\hline
\end{tabular}

Notes: $\mathrm{CA}=$ Caucasian, $\mathrm{AA}=\mathrm{African}$ American $\mathrm{MA}=$ Mexican American, $\mathrm{OR}=\mathrm{Other}$ Race, $\mathrm{OH}=$ Other Hispanic. 
NHANES reference study (Kelly, et al., 2009). The estimated regression coefficients were compared using the $95 \%$ confidence interval (CI) to estimates from similar groups within level II domains to determine if the slopes were homogeneous and, therefore, if the groups should be combined for analysis of covariance.

Next, the analysis examined survey regression level III domains based on permutations from two of three demographic groups. The 38 domains developed from the permutations from two groups were examined: gender with race/ethnicity (10); gender with age category (8); and race/ethnicity with age category (20). Again, the resulting estimates of slopes were compared within similar groups using the $95 \% \mathrm{CI}$ to determine if the domains from similar groups could be pooled.

Finally, each level IV domain from the permutations of the three demographic groups of gender, race/ethnicity, and age category were analyzed. This resulted in 40 different domains at level IV. The estimates of slopes from similar groups were compared using the $95 \%$ CI to determine if the domains from similar groups could be pooled. Thus, the data for a total of $90(1+11+38+40)$ domains with five imputations of data for each domain were analyzed resulting in 450 estimated regression coefficients (slopes) with their SEs, associated intercepts with their SEs, $p$ values and 95\% CIs.

Each domain's five estimated regression coefficients (slopes) with their SEs, associated intercepts with their SEs, probability values and 95\% CIs for each imputation were then averaged as outlined in the NHANES Technical Documentation (CDC. NCHS, 2010b). The intercepts and slopes for the five imputations were averaged using the arithmetic mean to produce a slope and an intercept for each domain. Computation of the $\mathrm{SE}$ for the respective slope and the SE for the respective intercept involved several steps. Initially, each SE for the slope was squared obtaining its variance. The within-imputation variance $(\mathrm{W})$ was calculated using the arithmetic mean of the five variances.

The between-imputation variance (B) was calculated, which was the sample variance for the five individual slopes.

$$
B=\sum_{n=1}^{5}\left(\text { slope }_{n}-\text { mean slope }\right)^{2} /(5-1)
$$

The total variance $(\mathrm{T})$ combined the between-imputation and the withinimputation variances.

$$
T=W+\frac{(5+1)}{5} B
$$

The SE for the slope was the square root of T. This process was repeated for each slope and intercept for the estimated regression lines from the 18 domains with different imputed data. The more conservative $95 \%$ confidence interval of the slope was calculated using the formula; slope $\pm 1.96 *$ (combined SE). 


\section{RESULTS}

This study included 5416 adolescents with 3235 males (59.7\%) and 2181 females (40.3\%). Demographic characteristics are summarized in Table 4.4. The adolescents' age at time of DXA exam ranged from 144 to 239 months. The BMI ranged from 13.14 to 54.31 with mean of 23.2 and standard deviation (SD) of 5.36. Weight ranged from 25.9 $\mathrm{kg}$ to $159.4 \mathrm{~kg}$ with mean of $64.9 \mathrm{~kg}$ and SD of $18.27 \mathrm{~kg}$. Height ranged from $133.0 \mathrm{~cm}$ to $193.9 \mathrm{~cm}$ with mean of $166.4 \mathrm{~cm}$ and SD of $10.64 \mathrm{~kg}$. The LLE BMC ranges, means and SDs for each of the five imputations of the total sample of adolescents are listed in Table 4.5.

There exists a positive linear relationship between BMI and LLE BMC for each domain examined; as BMI increased, LLE BMC also increased. The magnitude of the effect of BMI on LLE BMC was determined by the amount of the estimated slopes for each varied regression line. The greater the estimated slope, the greater the effect of BMI on LLE BMC accrual. The level I domain analysis produced a significant regression line $(p<0.0001)$ for each of the five imputations of DXA data, indicating the generally positive linear relationship.

Each of the 11 domains of level II; gender (2), race/ethnicity (5), and age category (4); had significant regression lines, indicating positive linear relationships. The LLE BMC was positively associated with BMI $(\mathrm{p}<0.0001)$ for each level II domain for each of the five imputations. (See Supplementary Information 4.1 for table of results for each imputation.) Within these domains of gender, race/ethnicity and age category, the relationship of BMI on LLE BMC differed. Because the slopes of the regression lines within each domain of the gender, race/ethnicity, and age category groups were heterogeneous, these domains could not be pooled and fitted to a single regression line.

All but two of the 38 domains of level III produced a significant regression line, indicating positive linear relationships. Examination of the level III domains from the 38 permutations based on two of the three demographic groups (gender-race/ethnicity, gender-age category, and race/ethnicity-age category) revealed a positive, linear relationship of BMI on LLE BMC for each domain, with the following exceptions: Other Race 18 - to 19 -year-olds $(p=0.11-0.16)$ and Other Hispanic 18 - to 19-year-olds $(p=0.70-0.73)$. (See Supplementary Information 4.1 for table of results for each imputation.) Within the level III domains of the gender with race/ethnicity groups, the estimated regression coefficients of LLE BMC on BMI were significantly different. Because of heterogeneity among the slopes of the regression lines within similar groups of level III (gender with race/ethnicity, gender with age category, and race/ethnicity with age category groupings), these domains could not be combined for analysis of covariance. The estimated slope was greater in males than in females within the same race/ethnicity group, indicating that males accrued more LLE BMC at higher rates at the same BMI than females regardless of race. The estimated regression coefficients of LLE $\mathrm{BMC}$ on BMI also differed significantly among the domains of the race/ethnicity with age category groups. Similarly, within the level III domains of the male-age category groups, there were differences in the estimated slopes, indicating that the relationship between BMI and LLE BMC varied by age in males. Examining the intercepts of the 
Table 4.4. Demographics of the adolescent sample from the 1999-2004 NHANES surveys who had DXA and BMI assessments $(\mathrm{N}=5416)$.

\begin{tabular}{lcc}
\hline Category & $\mathrm{n}$ & $\%$ \\
\hline Race & 1480 & \\
$\quad$ Caucasian & 1737 & 27.3 \\
African American & 1841 & 32.1 \\
Mexican American & 139 & 34.0 \\
Other Race & 219 & 2.6 \\
Other Hispanic & & 4.0 \\
Age & 1400 & \\
12-13 & 1287 & 25.8 \\
$14-15$ & 1326 & 23.8 \\
$16-17$ & 1403 & 24.5 \\
$18-19$ & & 25.9 \\
BMI & 188 & 3.5 \\
Underweight & 3346 & 61.8 \\
Normal & 858 & 15.8 \\
Overweight & 1024 & 18.9 \\
Obese & & \\
\hline
\end{tabular}

Note: DXA = dual energy X-ray absorptiometry; BMI = body mass index.

Table 4.5. Left lower extremity bone mineral content for each of the five imputations in the total sample $(\mathrm{N}=5416)$.

\begin{tabular}{lccc}
\hline Imputation & Range $(\mathrm{gm})$ & Mean $(\mathrm{gm})$ & SD $(\mathrm{gm})$ \\
\hline 1 & $141.08-912.69$ & 416.14 & 111.65 \\
2 & $141.08-939.16$ & 416.19 & 111.65 \\
3 & $141.08-912.67$ & 416.16 & 111.59 \\
4 & $141.08-913.88$ & 416.15 & 11.55 \\
5 & $141.08-912.67$ & 416.15 & 111.61 \\
\hline
\end{tabular}

Note: gm=gram. 
estimated regression lines, it was apparent that the domains with the larger intercepts were those domains, which contained the African American race/ethnicity group. This result is consistent with African Americans having a higher BMC than other race/ethnicity groups. Similarly, the male domains which contained those 14 years of age and older had higher intercepts than comparable female domains, indicating these males had greater BMC than females of similar age and race/ethnicity. (See Supplementary Information 4.1 for table of results for each imputation.)

All 90 domains produced statistically significant regression lines except for ten of the domains. Four of the five imputations for the domain Female Other Race 18- to 19year-olds were significant. See Supplementary Information 4.1 for tables with the intercept with SE, slope with SE, probability values and $95 \%$ CI for the slope of the regression line for each of the 90 domains for each of the five imputations. Also, Supplementary Information 4.1 contains a table with the averaged results.

The estimated regression lines were not the same from the level IV domains formed from the permutations of the three demographic groups among gender, race/ethnicity, and age category. This finding resulted in the necessity to consider 40 different domains, each domain with its unique regression line. Eight of these 40 domains did not produce statistically significant estimated regression coefficients. These eight domains were found exclusively in the underrepresented race/ethnicity groups of Other Race and Other Hispanic. (See Supplementary Information 4.1 for the results from all the data analysis.) For the remainder of this manuscript, the discussion will focus on the three main race/ethnicity groups from this study and their 24 domains. See Table 4.6 and Table 4.7 for the regression results after combining the results from the five imputations for each of these 24 domains. In examining these estimated regression lines it was clear that as BMI increased LLE BMC also increased for every domain, but at different rates depending on the domain. As the male domains aged, the rate of increase slowed, except for the Mexican American Male domains. Male Mexican American 14- to 15-year-olds had a greater estimated slope than Male Mexican American 12- to 14-year-olds. Also, Male Mexican American 18- to 19-year-olds had a greater estimated slope than Male Mexican American 16- to 17-year-olds. Thus for these domains with the larger slope, their LLE BMC increased at a faster rate for each unit of change in BMI compared to those domains with smaller slopes. The domain Male Caucasian 12- to 13-year-olds had the steepest slope, thus for this domain LLE BMC increased at the fastest rate for each unit of change in BMI.

Female domains exhibited a different pattern during aging. For Caucasian and Mexican American domains, rates of change in LLE BMC for each unit of BMI decreased across the younger three domains but rates increased among 18- to 19-yearolds. Female African American domains had the greatest rate of change in LLE BMC among 14- to 15-year-olds, then trended lower with the two older groups. Among Female African American domains, the 14- to 15-year-olds' LLE BMC is most affected by BMI. For the two domains of Female Caucasian 12- to 13-year-olds and Female Mexican American 12- to 13-year-olds, the increase in LLE BMC was most affected by changes in BMI. 
Table 4.6. Survey regression results for left lower extremity bone mineral content on body mass index based on the average of the five imputations (Level I).

\begin{tabular}{lccccccc}
\hline Domain & $\mathrm{N}$ & Intercept $^{1}$ & $\mathrm{SE}^{1}$ & Slope $^{1,2}$ & SE $^{1}$ & $\mathrm{p}$ & ${\text { Slope } 95 \% \mathrm{CI}^{1,2}}^{1}$ \\
\hline Total Population & 5416 & 211.06 & 10.65 & 8.83 & 0.48 & $<.0001$ & $7.89-9.79$ \\
\hline
\end{tabular}

Notes: ${ }^{1}$ Values rounded to two decimals, ${ }^{2}$ Estimated regression coefficients (slope) for comparable domains, which were not contained within a slope $95 \% \mathrm{CI}$, were considered statistically different. $\mathrm{SE}=$ standard error; $\mathrm{CI}=$ confidence interval. 
Table 4.7. Survey regression results left lower extremity bone mineral content on body mass index based on the average of the five imputations (Level IV).

\begin{tabular}{|c|c|c|c|c|c|c|c|}
\hline Domain & $\mathrm{n}$ & Intercept $^{1}$ & $\mathrm{SE}^{1}$ & Slope ${ }^{1,2}$ & $\mathrm{SE}^{1}$ & $\mathrm{p}$ & Slope $95 \% \mathrm{CI}^{1,2}$ \\
\hline Male Caucasian $12-13^{3}$ & 217 & 72.03 & 24.43 & 11.79 & 1.25 & $<.0001$ & $9.26-14.32$ \\
\hline Male Caucasian 14-15 & 208 & 266.67 & 26.25 & 7.92 & 1.20 & $<.0001$ & $5.57-10.27$ \\
\hline Male Caucasian 16-17 & 219 & 325.03 & 30.46 & 7.62 & 1.21 & $<.0001$ & $5.25-9.99$ \\
\hline Male Caucasian 18-19 & 211 & 371.17 & 22.91 & 6.25 & 1.01 & $<.0001$ & $4.28-8.23$ \\
\hline Male African Am. 12-13 & 278 & 170.67 & 15.66 & 9.28 & 0.77 & $<.0001$ & $7.77-10.78$ \\
\hline Male African Am. 14-15 & 258 & 296.59 & 21.25 & 8.50 & 0.89 & $<.0001$ & $6.75-10.24$ \\
\hline Male African Am. 16-17 & 293 & 380.48 & 25.18 & 7.46 & 1.08 & $<.0001$ & $5.34-9.59$ \\
\hline Male African Am. 18-19 & 229 & 420.99 & 33.33 & 7.06 & 1.38 & $<.0001$ & $4.35-9.76$ \\
\hline Male Mexican Am. 12-13 & 297 & 147.98 & 23.87 & 8.28 & 1.07 & $<.0001$ & $6.18-10.38$ \\
\hline Male Mexican Am. 14-15 & 258 & 221.91 & 24.70 & 8.86 & 1.03 & $<.0001$ & $6.83-10.90$ \\
\hline Male Mexican Am. 16-17 & 291 & 331.98 & 24.92 & 6.02 & 0.97 & $<.0001$ & $4.12-7.93$ \\
\hline Male Mexican Am. 18-19 & 268 & 293.77 & 21.19 & 7.74 & 0.87 & $<.0001$ & $6.03-9.44$ \\
\hline Male Other Race 12-133 & 13 & 180.63 & 68.00 & 7.82 & 3.34 & 0.0238 & $1.09-14.55$ \\
\hline Male Other Race 14-153 & 18 & 192.82 & 49.80 & 10.50 & 1.83 & $<.0001$ & $6.80-14.19$ \\
\hline Male Other Race 16-173 & 18 & 304.68 & 69.95 & 5.74 & 3.03 & 0.0652 & $5.25-9.99$ \\
\hline Male Other Race 18-193 & 30 & 343.64 & 83.41 & 6.44 & 3.63 & 0.0835 & $-0.89-13.76$ \\
\hline Male Other Hispanic 12-133 & 37 & 106.08 & 38.99 & 10.67 & 1.97 & $<.0001$ & $6.70-14.64$ \\
\hline Male Other Hispanic $14-15^{3}$ & 30 & 289.08 & 61.98 & 6.93 & 2.27 & 0.0038 & $2.36-11.50$ \\
\hline Male Other Hispanic $16-17^{3}$ & 38 & 395.72 & 71.92 & 3.22 & 2.83 & 0.2613 & $-2.48-8.92$ \\
\hline Male Other Hispanic $18-19$ & 24 & 393.99 & 160.24 & 6.26 & 7.15 & 0.3909 & $-7.77-20.28$ \\
\hline Female Caucasian $12-13^{3}$ & 150 & 167.77 & 20.03 & 6.87 & 0.91 & $<.0001$ & $5.03-8.71$ \\
\hline Female Caucasian $14-15^{3}$ & 147 & 232.95 & 30.14 & 5.51 & 1.36 & 0.0002 & $2.77-8.25$ \\
\hline Female Caucasian 16-17 & 149 & 297.92 & 16.61 & 3.64 & 0.68 & $<.0001$ & $2.32-4.96$ \\
\hline Female Caucasian 18-19 & 179 & 288.92 & 19.41 & 4.48 & 0.80 & $<.0001$ & $2.92-6.04$ \\
\hline Female African Am. $12-13^{3}$ & 190 & 257.61 & 18.53 & 5.29 & 0.79 & $<.0001$ & $3.70-6.88$ \\
\hline Female African Am. 14-15 & 166 & 261.84 & 12.42 & 6.05 & 0.49 & $<.0001$ & $5.05-7.04$ \\
\hline
\end{tabular}


Table 4.7. (Continued).

\begin{tabular}{lccccccc}
\hline Domain & $\mathrm{n}$ & Intercept $^{1}$ & $\mathrm{SE}^{1}$ & Slope $^{1,2}$ & $\mathrm{SE}^{1}$ & $\mathrm{p}$ & Slope 95\% CI $^{1,2}$ \\
\hline Female African Am. 16-17 & 144 & 299.13 & 16.32 & 4.77 & 0.62 & $<.0001$ & $3.55-5.98$ \\
Female African Am. 18-19 & 179 & 306.73 & 16.58 & 4.46 & 0.58 & $<.0001$ & $3.29-5.63$ \\
Female Mexican Am. 12-13 & 175 & 173.56 & 22.77 & 6.90 & 0.95 & $<.0001$ & $4.99-8.82$ \\
Female Mexican Am. 14-15 & 172 & 200.96 & 18.99 & 6.35 & 0.80 & $<.0001$ & $4.74-7.97$ \\
Female Mexican Am. 16-17 & 143 & 263.14 & 18.78 & 3.94 & 0.66 & $<.0001$ & $2.62-5.27$ \\
Female Mexican Am. 18-19 & 237 & 227.59 & 15.52 & 5.36 & 0.61 & $<.0001$ & $4.16-6.56$ \\
Female Other Race 12-13 & 17 & 207.57 & 83.62 & 5.17 & 3.73 & $\mathbf{0 . 1 7 2 3}$ & $-2.34-12.68$ \\
Female Other Race 14-15 & 12 & 163.64 & 108.15 & 7.83 & 4.79 & $\mathbf{0 . 1 0 9 4}$ & $-1.83-17.49$ \\
Female Other Race 16-17 & 12 & 270.54 & 90.71 & 3.44 & 3.98 & $\mathbf{0 . 3 9 2 2}$ & $-4.58-11.45$ \\
Female Other Race 18-19 & 19 & 242.99 & 40.57 & 4.52 & 1.66 & 0.0138 & $1.28-7.77$ \\
Female Other Hispanic 12-13 & 26 & 161.19 & 40.14 & 6.76 & 1.76 & 0.0004 & $3.22-10.30$ \\
Female Other Hispanic 14-15 & 18 & 120.48 & 41.28 & 10.17 & 1.70 & $<.0001$ & $6.80-13.53$ \\
Female Other Hispanic 16-17 & 19 & 236.03 & 42.63 & 6.19 & 1.82 & 0.0031 & $2.63-9.76$ \\
Female Other Hispanic 18-19 & 27 & 220.03 & 67.04 & 4.80 & 2.67 & $\mathbf{0 . 0 7 9 6}$ & $-0.59-10.18$ \\
\hline
\end{tabular}

Notes: ${ }^{1}$ Values rounded to two decimals, ${ }^{2}$ Estimated regression coefficients (slope) for comparable domains, which were not contained within a slope $95 \%$ CI, were considered statistically different., ${ }^{3}$ Values same for all five imputations; Bold $\mathrm{p}$ values were not statistically significant. $\mathrm{SE}=$ standard error; $\mathrm{CI}=$ confidence interval. 
As mentioned previously, the plots were also examined. Generally, the functional form of the relationship between LLE BMC (independent variable) on BMI (dependent variable) was linear. There may be some curvilinear component to this relationship. This presumed curvilinearity appears when examining the estimated regression lines superimposed over the plots of the data for each domain. In Figure 4.1, there is an example of the plots and depicts the data from Imputation 1 for the domain of Male Caucasian 12- to 13 year olds with the estimated regression line superimposed on the plot. The presumed curvilinearity may be attributable to heteroscedasticity due to increasing variability in LLE BMC as BMI increases. Also, in Figure 4.1, notice the overall fan shape of the scatter plot. This plot is similar to the fan shape of the CDC BMI for age graph (CDC, 2010). In Figure 4.2, the same domain is plotted, except the data points are identified by the weight category (underweight, normal weight, overweight and obese). These two plots are representative of the plots for the other domains. (See Supplementary Information $\mathbf{4 . 2}$ and $\mathbf{4 . 3}$ for the plots from the other domains.)

In Figure 4.2 large variation in BMC within the weight classifications are evident. For example, one underweight adolescent had more gm of BMC than several normal weight adolescents, overweight adolescents, and obese adolescents. Similarly, there are a few obese adolescents with less LLE BMC than those having lower BMIs. Despite these variations, there exists a clear linear relationship between LLE BMC and BMI for each of the 24 gender, race/ethnicity, and age category domains for this NHANES adolescent population.

\section{DISCUSSION}

This study provided the first look at the relationship between BMI and LLE BMC across an entire spectrum of weight categories from underweight to obese based on a large sample population of 5416 adolescents. The results of this study support the conclusions of prior studies (Cobayashi, et al., 2005; El Hage, Jacob, Moussa, Benhamou, \& Jaffre, 2009; Ellis, et al., 2003; Leonard, et al., 2004; Sayers \& Tobias, 2010), which reported greater body weight or BMI was associated with higher whole body or region specific BMC/ bone mass or bone density.

The results of this study are contrary to the conclusions that Goulding et al (2000) reached in their study looking at children and adolescents. They concluded that overweight and obese youth had low BMC for their body weight. Goulding et al looked at the entire body total BMC and not just the weight bearing area of the LE. It is understandable why this study examining the LLE BMC would have different results and reach different conclusions, since the bones of the LE support the entire weight during weight bearing activities.

The BMC of adolescents must be examined, just as BMI for adolescents is examined, based on age and gender. The results of this study support the position that, when examining BMC of adolescents, there are gender, race/ethnicity, and age differences to consider. This is consistent with previous research (Bachrach, et al., 1999; Kalkwarf, et al., 2007; Kelly, et al., 2009). 


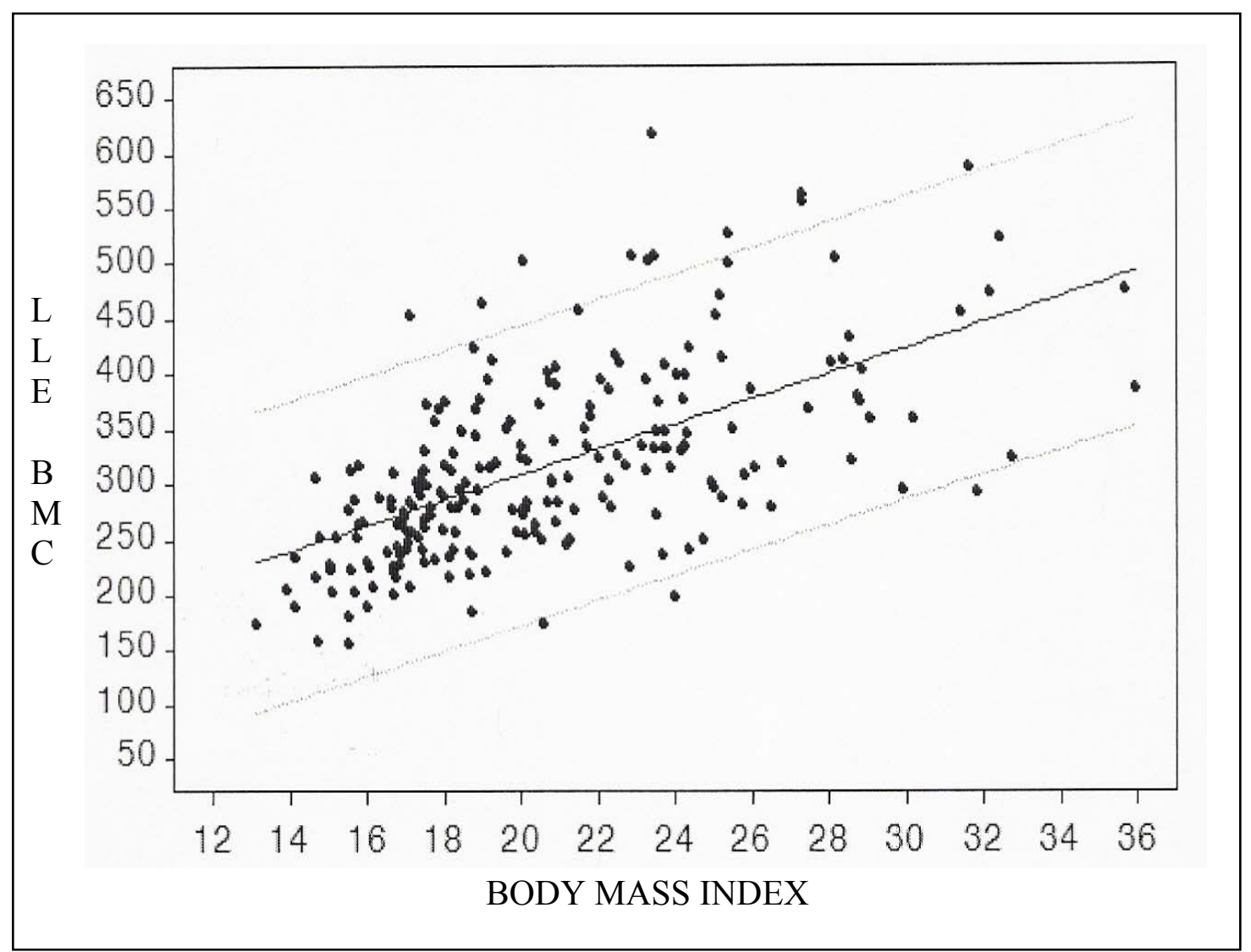

Figure 4.1. Plot of left lower extremity on body mass index for male Caucasian 12- to 13-year-olds domain with the estimated regression line superimposed.

Notes: LLE=left lower extremity, BMC=bone mineral content. 


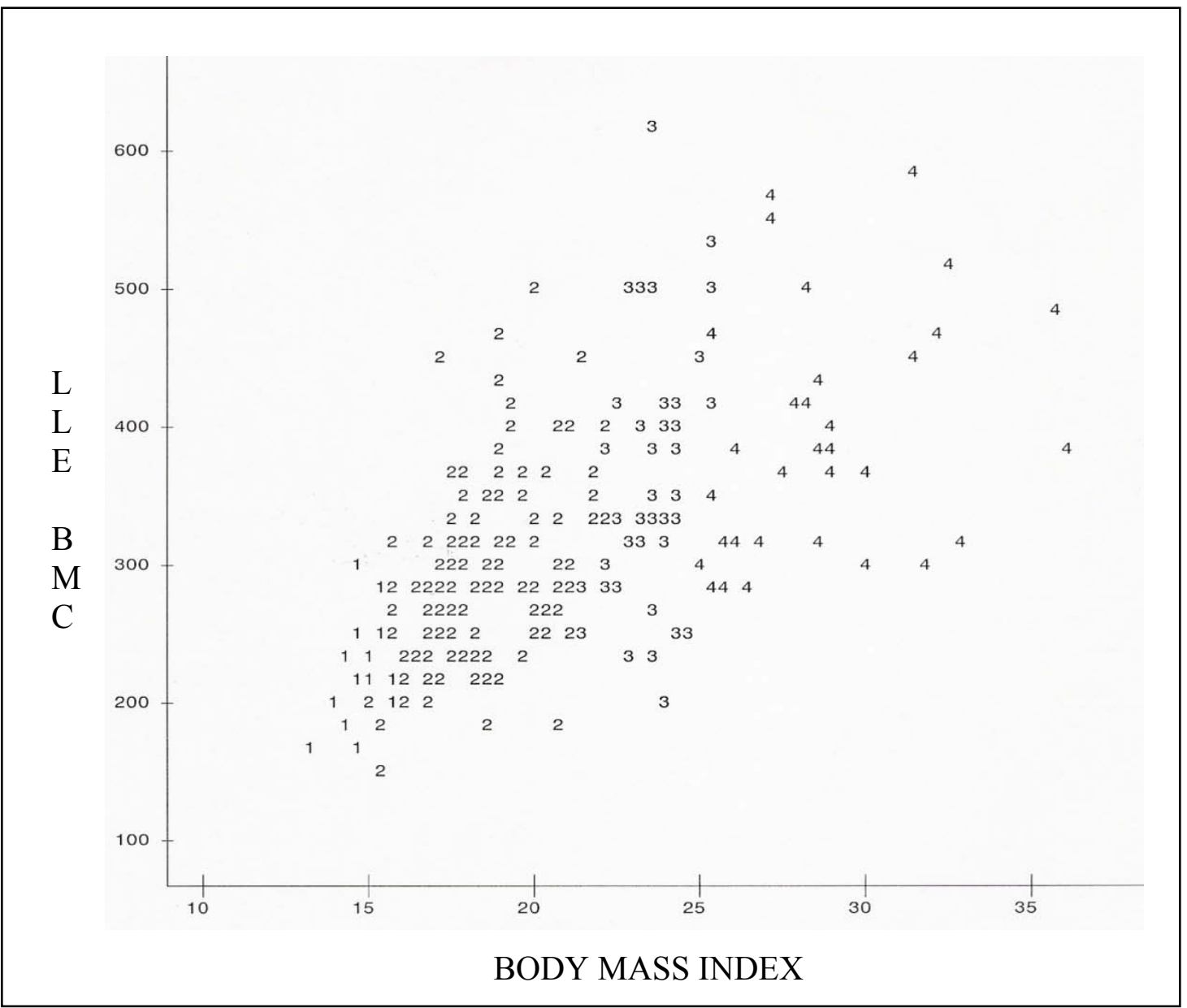

Figure 4.2. Plot of left lower extremity bone mineral content on body mass index for male Caucasian 12- to 13-year-olds domain by weight category.

Note: $\mathrm{LLE}=$ left lower extremity, $\mathrm{BMC}=$ bone mineral content, $1=$ =underweight; $2=$ normal weight; $3=$ overweight; and 4=obese. 
This study could not control for the effect of puberty on the BMC (Magarey, et al., 1999) because Tanner staging or pubertal status was not assessed as part of NHANES. Puberty has a tremendous impact on BMC accrual with increases of growth and sex hormones. Over $25 \%$ of the total adult BMC is acquired during the two year period incorporating the pubertal growth spurt of adolescence (Bailey, et al., 2000) "with up to $60 \%$ acquired during the remaining peripubertal years" (Loud \& Gordon, 2006, p. 1026). Additionally, this study could not control for the effect of physical activity on BMC (Volgyi et al.) for this NHANES population. Physical activity data for this population were collected from different sources; sometimes from survey participants and other times from proxy surrogates. The physically active adolescents are performing more weight-bearing activities, causing more tissue strain on the bone stimulating more BMC accrual. Physically active male and female adolescents are known to gain $9 \%$ and $17 \%$ more total body BMC, respectively, than their inactive peers.(Bailey, McKay, Mirwald, Crocker, \& Faulkner, 1999) Similarly, vitamin D levels could not be controlled due to identified drift among the lab results during NHANES. Vitamin D is necessary for the calcium accretion in BMC accrual. Low vitamin D status (Cashman et al., 2008) has been shown to adversely affect BMC in adolescents.

\section{Clinical Implications}

This study emphasizes the fact that when assessing an adolescent's BMC or bone density in relation to his or her BMI, the assessment must consider the adolescent's gender, race/ethnicity, and age. The general results of this study are that the higher BMI implies greater LLE BMC. However, this association may not be the case for each individual. The large variation exhibited within the weight classifications, demonstrated by the plots, reveal that having a high BMI does not necessarily equate to having bigger bones (as indicated by higher LLE BMC), even within the gender, race/ethnicity and age group. If there is clinical concern about body composition or BMC accrual, then the adolescent should receive a whole body DXA scan.

Prior research by Taylor et al. (2006) illustrates the negative orthopedic complications of higher BMI. Despite the positive association between BMC and BMI found in this study, it is understandable that the joints, especially the knees, will receive the most negative orthopedic impact from higher levels of BMI. The forces of impact are transmitted to the weight bearing joints. Clinicians, in conjunction with the adolescent and the family, need to consider developing low impact exercise regime for high BMI adolescents to protect and preserve the joint from excessive impact. Despite such complications, these adolescents with higher BMI levels need extra encouragement, incentive and guidance to be as active as possible.

\section{Research Implications}

The most immediate implications for further research should be the completion of similar studies with this same NHANES adolescent population. The next proposed study would be to examine the relationship between LLE lean mass and BMI in this population. 
Then, the third study would be comparing the relationships between LLE BMC and BMI found in this current study to the relationships between LLE lean mass and BMI found in the proposed study for this same NHANES adolescent population. The role of BMI as a modulator on the bone-muscle unit can be more fully explored by examining these relationships found in these additional studies.

As research advances in the reduction of obesity during adolescence, researchers should use caution to understand the effect of the reduction of BMI on developing bone mass during a critical time of bone accrual. Reducing weight can reduce bone mass during adolescence (Rourke, et al., 2003). Research should examine the effects of proper nutritional and vitamin supplementation to preserve BMC while reducing BMI.

Additionally, research should focus on correct physical activity that reduces stress to the joints, but preserves BMC while reducing BMI.

\section{Theoretical Implications}

This present study examined the role of BMI as a modulator of the mechanostats affecting the bone accrual of the bone-muscle unit in adolescents (Schoenau \& Frost, 2002) as outlined in Frost's Mechanostat Theory. The findings of this study support the BMI as a modulator of the bone accrual mechanostat. Gender, race/ethnicity, and age have an effect on the relationship between BMI and BMC.

Despite the primarily linear relationship between LLE BMC and BMI, there may be an unidentified curvilinear component to this relationship, as depicted by the fan shape of data in the plots, between these two variables. Such a curvilinear component implies that there may be a level of BMI where BMC plateaus and no longer increases at the same rate. Although that point may theoretically exist, it is beyond the scope of this study to estimate that point of inflection. Currently the measurement of the BMC variable is limited to the weight and height restrictions of the DXA scanner and its scanning field.

Another implication of the fan shape is the residuals (the distance the datum plot is off the estimated regression line) may not be independent of BMI. Instead, as BMI increases, the residuals may also increase. Restricting the domains to one-year intervals may reduce the apparent heteroscedasticity. In addition, adjusting for height and weight as separate covariates, rather than combined in BMI, may also address this problem.

\section{SUMMARY}

There is a positive linear relationship between LLE BMC and BMI among US adolescents age 12 to 19 years old. This relationship is dependent on the combination of three demographic factors: the gender, the race/ethnicity, and the age of the adolescent. These findings have important clinical, theoretical and research implications in light of our ever increasing obese population. 


\section{LIST OF REFERENCES}

Ackerman, A., Thornton, J. C., Wang, J., Pierson, R. N., Jr., \& Horlick, M. (2006). Sex difference in the effect of puberty on the relationship between fat mass and bone mass in 926 healthy subjects, 6 to 18 years old. Obesity, 14(5), 819-825.

Bachrach, L. K., Hastie, T., Wang, M. C., Narasimhan, B., \& Marcus, R. (1999). Bone mineral acquisition in healthy Asian, Hispanic, black, and Caucasian youth: a longitudinal study. Journal of Clinical Endocrinology \& Metabolism, 84(12), $4702-4712$.

Bailey, D. A., Martin, A. D., McKay, H. A., Whiting, S., \& Mirwald, R. (2000). Calcium accretion in girls and boys during puberty: a longitudinal analysis. Journal of Bone and Mineral Research, 15(11), 2245-2250.

Bailey, D. A., McKay, H. A., Mirwald, R. L., Crocker, P. R., \& Faulkner, R. A. (1999). A six-year longitudinal study of the relationship of physical activity to bone mineral accrual in growing children: the university of Saskatchewan bone mineral accrual study. Journal of Bone and Mineral Research, 14(10), 1672-1679.

Beck, T. J., Ruff, C. B., Shaffer, R. A., Betsinger, K., Trone, D. W., \& Brodine, S. K. (2000). Stress fracture in military recruits: gender differences in muscle and bone susceptibility factors. Bone, 27(3), 437-444.

Bishop, N., Braillon, P., Burnham, J., Cimaz, R., Davies, J., Fewtrell, M., . . Bianchi, M. L. (2008). Dual-energy X-ray aborptiometry assessment in children and adolescents with diseases that may affect the skeleton: the 2007 ISCD Pediatric Official Positions. Journal of Clinical Densitometry, 11(1), 29-42.

Bonjour, J. P., Theintz, G., Buchs, B., Slosman, D., \& Rizzoli, R. (1991). Critical years and stages of puberty for spinal and femoral bone mass accumulation during adolescence. Journal of Clinical Endocrinology \& Metabolism, 73(3), 555-563.

Braillon, P. M., Berard, J., Chatelain, P., \& Pracros, J. P. (2002). [Dual energy x-ray absorptiometry assessment of the bone mineral content and body composition during growth]. Journal de Radiologie, 83(5), 627-633.

Buntain, H. M., Schluter, P. J., Bell, S. C., Greer, R. M., Wong, J. C., Batch, J., . . Wainwright, C. E. (2006). Controlled longitudinal study of bone mass accrual in children and adolescents with cystic fibrosis. Thorax, 61(2), 146-154.

Cashman, K., Hill, T., Cotter, A., Boreham, C., Dubitzky, W., Murray, L., . . Kiely, M. (2008). Low vitamin D status adversely affects bone health parameters in adolescents. American Journal of Clinical Nutrition, 87(4), 1039-1044. 
CDC, Division of Nutrition, Physical Activity and Obesity, National Center for Chronic Disease Prevention and Health Promotion. (2010, March 31). Obesity and Overweight for Professionals: Childhood Retrieved June 2, 2010, from http://www.cdc.gov/obesity/childhood/index.html

CDC. NCHS. (2010a). National Health and Nutrition Examination Survey Data. Retrieved June 26, 2010, from http://www.cdc.gov/nchs/nhanes.htm

CDC. NCHS. (2010b). National Health and Nutrition Examination Survey Examination Protocol. Retrieved June 26, 2010, from http://www.cdc.gov/nchs/nhanes.htm

CDC. NCHS. (2010c). National Health and Nutrition Examination Survey Questionnaire. Retrieved June 26, 2010, from http://www.cdc.gov/nchs/nhanes.htm

Cobayashi, F., Lopes, L. A., \& Taddei, J. A. (2005). Bone mineral density in overweight and obese adolescents. Jornal de Pediatria, 81(4), 337-342.

Daniels, S. R., Arnett, D. K., Eckel, R. H., Gidding, S. S., Hayman, L. L., Kumanyika, S., ... Williams, C. L. (2005). Overweight in children and adolescents: pathophysiology, consequences, prevention, and treatment. Circulation, 111(15), 1999-2012.

Davies, J. H., Evans, B. A., \& Gregory, J. W. (2005). Bone mass acquisition in healthy children. Archives of Diseases in Childhood, 90(4), 373-378.

De Schepper, J., Van den Broeck, M., \& Jonckheer, M. H. (1995). Study of lumbar spine bone mineral density in obese children. Acta Paediatrica, 84(3), 313-315.

El Hage, R., Jacob, C., Moussa, E., Benhamou, C. L., \& Jaffre, C. (2009). Total body, lumbar spine and hip bone mineral density in overweight adolescent girls: decreased or increased? Journal of Bone \& Mineral Metabolism, 27(5), 629-633.

Ellis, K. J., Shypailo, R. J., Wong, W. W., \& Abrams, S. A. (2003). Bone mineral mass in overweight and obese children: diminished or enhanced? Acta Diabetologica, 40 Suppl 1, S274-277.

Fernandez-Garcia, D., Rodriguez, M., Garcia Aleman, J., Garcia-Almeida, J. M., Picon, M. J., Fernandez-Aranda, F., \& Tinahones, F. J. (2009). Thin healthy women have a similar low bone mass to women with anorexia nervosa. British Journal of Nutrition, 102(5), 709-714.

Fryar, C. D., \& Ogden, C. L. (2009, July 2009). Prevalence of Underweight Among Children and Adolescents: United States, 2003-2006. Health E-Stat Retrieved May 3, 2011, from http://www.cdc.gov/nchs/data/hestat/underweight/underweight_children.pdf 
Galusca, B., Zouch, M., Germain, N., Bossu, C., Frere, D., Lang, F., . . Estour, B. (2008). Constitutional thinness: unusual human phenotype of low bone quality. Journal of Clinical Endocrinology \& Metabolism, 93(1), 110-117.

Gilsanz, V., Chalfant, J., Kalkwarf, H., Zemel, B., Lappe, J., Oberfield, S., . . Winer, K. (2011). Age at onset of puberty predicts bone mass in young adulthood. Journal of Pediatrics, 158(1), 100-105, 105 e101-102.

Gordon, C. M., Bachrach, L. K., Carpenter, T. O., Crabtree, N., El-Hajj Fuleihan, G., Kutilek, S., . . Kalkwarf, H. J. (2008). Dual energy X-ray absorptiometry interpretation and reporting in children and adolescents: the 2007 ISCD Pediatric Official Positions. Journal of Clinical Densitometry, 11(1), 43-58.

Goulding, A., Grant, A. M., \& Williams, S. M. (2005). Bone and body composition of children and adolescents with repeated forearm fractures. Journal of Bone \& Mineral Research, 20(12), 2090-2096.

Goulding, A., Jones, I. E., Taylor, R. W., Williams, S. M., \& Manning, P. J. (2001). Bone mineral density and body composition in boys with distal forearm fractures: a dual-energy x-ray absorptiometry study. Journal of Pediatrics, 139(4), 509-515.

Goulding, A., Taylor, R. W., Jones, I. E., Manning, P. J., \& Williams, S. M. (2002). Spinal overload: a concern for obese children and adolescents? Osteoporosis International, 13(10), 835-840.

Goulding, A., Taylor, R. W., Jones, I. E., McAuley, K. A., Manning, P. J., \& Williams, S. M. (2000). Overweight and obese children have low bone mass and area for their weight. International Journal of Obesity Related Metabolic Disorders, 24(5), 627-632.

Jee, W. S. (2000). Principles in bone physiology. Journal of Musculoskeletal and Neuronal Interaction, 1(1), 11-13.

Kalkwarf, H. J., Zemel, B. S., Gilsanz, V., Lappe, J. M., Horlick, M., Oberfield, S., . . Shepherd, J. A. (2007). The bone mineral density in childhood study: bone mineral content and density according to age, sex, and race. Journal of Clinical Endocrinology \& Metabolism, 92(6), 2087-2099.

Kelly, T. L., Wilson, K. E., \& Heymsfield, S. B. (2009). Dual energy X-Ray absorptiometry body composition reference values from NHANES. Public Library of Science One, 4(9), e7038.

Leonard, M. B., Shults, J., Wilson, B. A., Tershakovec, A. M., \& Zemel, B. S. (2004). Obesity during childhood and adolescence augments bone mass and bone dimensions. American Journal of Clinical Nutrition, 80(2), 514-523.

Loud, K. J., \& Gordon, C. M. (2006). Adolescent bone health. Archives of Pediatrics \& Adolescent Medicine, 160(10), 1026-1032. 
Magarey, A. M., Boulton, T. J., Chatterton, B. E., Schultz, C., Nordin, B. E., \& Cockington, R. A. (1999). Bone growth from 11 to 17 years: relationship to growth, gender and changes with pubertal status including timing of menarche. Acta Paediatr, 88(2), 139-146.

Misra, M., Aggarwal, A., Miller, K. K., Almazan, C., Worley, M., Soyka, L. A., . . Klibanski, A. (2004). Effects of anorexia nervosa on clinical, hematologic, biochemical, and bone density parameters in community-dwelling adolescent girls. Pediatrics, 114(6), 1574-1583.

National Osteoporosis Foundation. (2008). Clinician's guide to prevention and treatment of osteoporosis. Washington, DC: National Osteoporosis Foundation.

Nattiv, A. (2000). Stress fractures and bone health in track and field athletes. Journal of Science \& Medicine in Sports, 3(3), 268-279.

Office of Surgeon General. (2004). Bone Health and Osteoporosis: A Report of the Surgeon General Retrieved Feb. 2, 2011, from http://www.surgeongeneral.gov/library/bonehealth/chapter_6.html

Ogden, C. L., Carroll, M. D., Curtin, L. R., Lamb, M. M., \& Flegal, K. M. (2010). Prevalence of high body mass index in US children and adolescents, 2007-2008. JAMA, 303(3), 242-249.

Ogden, C. L., \& Flegal, K. M. (2010). Changes in terminology for childhood overweight and obesity. National Health Statistics Report(25), 1-5.

Polit, Denise F. , \& Beck, Cheryl T. (2008). Nursing research: Generating and assessing evidence for nursing practice (8th ed.). Philadelphia: Lippincott Williams \& Wilkins.

Pollack, Peter. (2008). The impact of childhood obesity on bones. AAOS Now Retrieved June 3, 2010, from http:/www.aaos.org/news/aaosnow/sep08/clinical9.asp

Rauch, F. (2005). Bone growth in length and width: the yin and yang of bone stability. Journal of Musculoskeletal \& Neuronal Interactions, 5(3), 194-201.

Reid, I. R. (2002). Relationships among body mass, its components, and bone. Bone, 31(5), 547-555.

Rourke, K. M., Brehm, B. J., Cassell, C., \& Sethuraman, G. (2003). Effect of weight change on bone mass in female adolescents. Journal of the American Dietetic Association, 103(3), 369-372.

Sayers, A., \& Tobias, J. H. (2010). Fat mass exerts a greater effect on cortical bone mass in girls than boys. Journal of Clinical Endocrinology \& Metabolism, 95(2), 699706. 
Schoeller, D. A., Tylavsky, F. A., Baer, D. J., Chumlea, W. C., Earthman, C. P., Fuerst, T., . . Borrud, L. G. (2005). QDR 4500A dual-energy X-ray absorptiometer underestimates fat mass in comparison with criterion methods in adults. American Journal of Clinical Nutrition, 81(5), 1018-1025.

Schoenau, E., \& Frost, H. M. (2002). The "muscle-bone unit" in children and adolescents. Calcified Tissue International, 70(5), 405-407.

Schwarz, Steven M, \& Freemark, Michael (2010, April 13). Obesity. eMedicine Retrieved June 3, 2010, from http://emedicine.medscape.com/article/98533overview

Soyka, L. A., Misra, M., Frenchman, A., Miller, K. K., Grinspoon, S., Schoenfeld, D. A., \& Klibanski, A. (2002). Abnormal bone mineral accrual in adolescent girls with anorexia nervosa. Journal of Clinical Endocrinology \& Metabolism, 87(9), 41774185.

Taylor, E. D., Theim, K. R., Mirch, M. C., Ghorbani, S., Tanofsky-Kraff, M., AdlerWailes, D. C., ... Yanovski, J. A. (2006). Orthopedic complications of overweight in children and adolescents. Pediatrics, 117(6), 2167-2174.

Volgyi, E., Lyytikainen, A., Tylavsky, F. A., Nicholson, P. H., Suominen, H., Alen, M., \& Cheng, S.(2010). Long-term leisure-time physical activity has a positive effect on bone mass gain in girls. Journal of Bone \& Mineral Research, 25(5), 10341041.

Wahner, Heinz W, \& Fogelman, Ignac. (1994). The evaluation of osteoporosis: dual energy $x$-ray absorptiometry in clinical practice. London: Martin Dunitz.

Whiting, S. J., Vatanparast, H., Baxter-Jones, A., Faulkner, R. A., Mirwald, R., \& Bailey, D. A. (2004). Factors that affect bone mineral accrual in the adolescent growth spurt. Journal of Nutrition, 134(3), 696S-700S. 


\section{APPENDIX. UNIVERSITY OF TENNESSEE HEALTH SCIENCE CENTER INSTITUTIONAL REVIEW BOARD LETTER OF APPROVAL}

\begin{tabular}{lr}
\hline THE UNIVERSITY OF TENNESSEE \\
Health Science Center \\
\hline Institutional Review Board \\
910 Madison Avenue, Suite 600 \\
Memphis, TN 38163 \\
Tel: (901) 448-4824
\end{tabular}

26 October 2010

James Randall Post, MSN

UTHSC - CON - Nursing- Acute/ Chronic

Re: 10-01050-XM

Study Title: The Relationship of Body Mass Index to Lower Extremity Bone Mass, Lean Mass and Their Ratio in the NHANES Adolescent Population

Dear Dr. Post:

The Administrative Section of the UTHSC Institutional Review Board (IRB) reviewed your application for the above referenced project. The IRB determined that your application is eligible for exempt review under 45 CFR 46.102(f) in that it does not involve "human subjects" as defined therein. In accord with 45 CFR 46.116(d), informed consent is waived. Your application has been determined to comply with proper consideration for the rights and welfare of human subjects and the regulatory requirements for the protection of human subjects. This letter constitutes full approval of your application for the above referenced study.

This study may not be initiated until you receive approval from the institution(s) where the research is being conducted.

In the event that volunteers are to be recruited using solicitation materials, such as brochures, posters, web-based advertisements, etc., these materials must receive prior approval of the IRB.

Any alterations (revisions) in the protocol must be promptly submitted to and approved by the UTHSC Institutional Review Board prior to implementation of these revisions. You have individual responsibility for reporting to the Board in the event of unanticipated or serious adverse events and subject deaths.

Sincerely,

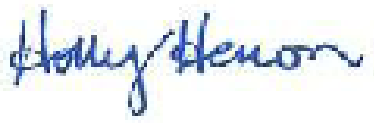

Signature applied by Holly A Herron on 10/26/2010 11:05:53 AM CDT

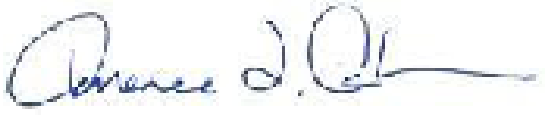




\section{VITA}

James (Randy) Post was born in 1956 in Birmingham, AL and graduated from Jones Valley High School in 1974. Following high school he received a four-year academic Reserve Officer Training Corps (ROTC) scholarship from the United States (US) Army to attend Vanderbilt University in Nashville, TN. He graduated from Vanderbilt in 1978 with Bachelor of Arts in Mathematics and was commissioned as a second lieutenant in the Field Artillery (FA) of the US Army. He served in a number of assignments and locations including as a ROTC Instructor at Murray State University, Murray, KY. While at Murray State, he obtained his Masters of Science in Mathematics in 1992 and was inducted into Pi Mu Epsilon, National Mathematics Honor Society. After the conclusion of the First Gulf War, he left active military service in 1992 having attained the rank of Major. He returned to Murray State University and taught mathematics directing the developmental mathematics program. In 1993 he enrolled in the Family Nurse Practitioner (FNP) Bridge Program at Vanderbilt University. He graduated in 1995 with his Masters of Science in Nursing as a FNP and was inducted in Sigma Theta Tau, International Honor Society of Nursing. In 2007 he was selected to attend the Long Term Health Education and Training (LTHET) program to pursue a Doctor of Philosophy in Nursing with full financial support for three years. In 2008 Randy was accepted into the nursing doctoral program at The University of Tennessee Health Science Center in Memphis, TN. His dissertation research focused on bone mass and body composition assessment in adolescents and young adults. He will graduate with a degree of Doctor of Philosophy in Nursing in May 2011. He has been assigned to the Center for Nursing Science \& Clinical Inquiry (CNSCI) at Brooke Army Medical Center in San Antonio, Texas. 